\title{
Global and Arctic effective radiative forcing of anthropogenic gases and aerosols in MRI-ESM2.0
}

Naga Oshima* (D), Seiji Yukimoto, Makoto Deushi, Tsuyoshi Koshiro, Hideaki Kawai, Taichu Y. Tanaka and Kohei Yoshida

\begin{abstract}
The effective radiative forcing (ERF) of anthropogenic gases and aerosols under present-day conditions relative to preindustrial conditions is estimated using the Meteorological Research Institute Earth System Model version 2.0 (MRI-ESM2.0) as part of the Radiative Forcing Model Intercomparison Project (RFMIP) and Aerosol and Chemistry Model Intercomparison Project (AerChemMIP), endorsed by the sixth phase of the Coupled Model Intercomparison Project (CMIP6). The global mean total anthropogenic net ERF estimate at the top of the atmosphere is $1.96 \mathrm{~W} \mathrm{~m}^{-2}$ and is composed primarily of positive forcings due to carbon dioxide $\left(1.85 \mathrm{~W} \mathrm{~m}^{-2}\right)$, methane $\left(0.71 \mathrm{~W} \mathrm{~m}^{-2}\right)$, and halocarbons $\left(0.30 \mathrm{~W} \mathrm{~m}^{-2}\right)$ and negative forcing due to the total aerosols $\left(-1.22 \mathrm{~W} \mathrm{~m}^{-2}\right)$. The total aerosol ERF consists of $23 \%$ from aerosol-radiation interactions $\left(-0.32 \mathrm{~W} \mathrm{~m}^{-2}\right), 71 \%$ from aerosol-cloud interactions $(-0.98 \mathrm{~W}$ $\mathrm{m}^{-2}$ ), and slightly from surface albedo changes caused by aerosols $\left(0.08 \mathrm{~W} \mathrm{~m}^{-2}\right)$. The ERFs due to aerosol-radiation interactions consist of opposing contributions from light-absorbing black carbon (BC) $\left(0.25 \mathrm{~W} \mathrm{~m}^{-2}\right)$ and from lightscattering sulfate $\left(-0.48 \mathrm{~W} \mathrm{~m}^{-2}\right)$ and organic aerosols $\left(-0.07 \mathrm{~W} \mathrm{~m}^{-2}\right)$ and are pronounced over emission source regions. The ERFs due to aerosol-cloud interactions (ERFaci) are prominent over the source and downwind regions, caused by increases in the number concentrations of cloud condensation nuclei and cloud droplets in low-level clouds. Concurrently, increases in the number concentration of ice crystals in high-level clouds (temperatures $<-$ $38^{\circ} \mathrm{C}$ ), primarily induced by anthropogenic BC aerosols, particularly over tropical convective regions, cause both substantial negative shortwave and positive longwave ERFaci values in MRI-ESM2.0. These distinct forcings largely cancel each other; however, significant longwave radiative heating of the atmosphere caused by high-level ice clouds suggests the importance of further studies on the interactions of aerosols with ice clouds. Total anthropogenic net ERFs are almost entirely positive over the Arctic due to contributions from the surface albedo reductions caused by BC. In the Arctic, BC provides the second largest contribution to the positive ERFs after carbon dioxide, suggesting a possible important role of BC in Arctic surface warming.
\end{abstract}

Keywords: Radiative forcing, Aerosols, Short-lived climate forcer, Black carbon, Greenhouse gas, Arctic, Earth system model, CMIP6, RFMIP, AerChemMIP

\footnotetext{
* Correspondence: oshima@mri-jma.go.jp

Meteorological Research Institute, 1-1 Nagamine, Tsukuba, Ibaraki 305-0052,

Japan
}

(c) The Author(s). 2020 Open Access This article is licensed under a Creative Commons Attribution 4.0 International License, which permits use, sharing, adaptation, distribution and reproduction in any medium or format, as long as you give appropriate credit to the original author(s) and the source, provide a link to the Creative Commons licence, and indicate if changes were made. The images or other third party material in this article are included in the article's Creative Commons licence, unless indicated otherwise in a credit line to the material. If material is not included in the article's Creative Commons licence and your intended use is not permitted by statutory regulation or exceeds the permitted use, you will need to obtain permission directly from the copyright holder. To view a copy of this licence, visit http://creativecommons.org/licenses/by/4.0/. 


\section{Introduction}

Anthropogenic gases and aerosols affect radiation balance on the Earth and therefore cause climate change over the industrial era. Well-mixed greenhouse gases, including carbon dioxide $\left(\mathrm{CO}_{2}\right)$, methane $\left(\mathrm{CH}_{4}\right)$, nitrous oxide $\left(\mathrm{N}_{2} \mathrm{O}\right)$, and halocarbons, have lifetimes that are much longer than a few years and accordingly impact the climate over long time scales (Myhre et al. 2013). Atmospheric aerosols have a typical lifetime of 1 day to 2 weeks in the troposphere and significantly influence reginal and global climates. Aerosol particles modify the radiation balance directly through scattering and the absorption of shortwave (SW) radiation (aerosol-radiation interactions) and indirectly through cloud modification by serving as cloud condensation nuclei $(\mathrm{CCN})$ and ice nucleating particles (INPs) for both SW and longwave (LW) radiation (aerosol-cloud interactions) (Boucher et al. 2013). The deposition of light-absorbing aerosols, such as black carbon (BC), on snow and ice can also affect the radiation due to reduction of the surface albedo (e.g., Hansen and Nazarenko 2004; Flanner et al. 2007). Because BC strongly absorbs SW radiation and therefore leads to atmospheric heating, climate responses to BC in the Earth system are complex (e.g., Jacobson 2002; Bond et al. 2013; Stohl et al. 2015; Kaiho et al. 2016; Kaiho and Oshima 2017; Suzuki and Takemura 2019; Takemura and Suzuki 2019), and the role of $\mathrm{BC}$ has been recognized as being particularly important in the Arctic (e.g., Arctic Monitoring and Assessment Programme (AMAP) 2015; Sand et al. 2015; Mahmood et al. 2016).

Effective radiative forcing (ERF) has been recognized as a useful indicator of the eventual temperature response, especially for aerosols, because ERF accounts for rapid adjustments (Myhre et al. 2013). In the Intergovernmental Panel on Climate Change fifth Assessment Report (IPCC AR5; Myhre et al. 2013), the total anthropogenic net (SW plus LW) ERF at the top of the atmosphere (TOA) over the industrial era (years 17502011) was estimated to be 2.3 (1.1 to 3.3$) \mathrm{W} \mathrm{m}^{-2}$, where the uncertainty values in the parenthesis represent the 5-95\% (90\%) confidence range. The total well-mixed greenhouse gas ERF was estimated to be 2.83 (2.26 to 3.40) $\mathrm{W} \mathrm{m} \mathrm{m}^{-2}$. Aerosols partially offset the well-mixed greenhouse gas ERF in the total anthropogenic ERF. In IPCC AR5, the aerosol ERF was distinguished by forcing processes arising from aerosol-radiation interactions (ERFari) and aerosol-cloud interactions (ERFaci). The total aerosol net ERF (ERFari+aci, excluding the effect of light-absorbing aerosols on snow and ice) was estimated to be -0.9 ( -1.9 to 0.1$) \mathrm{W} \mathrm{m}^{-2}$, and ERFari was estimated to be -0.45 ( -0.95 to 0.05$) \mathrm{W} \mathrm{m}^{-2}$. The total aerosol ERFaci, which is defined as ERFari+aci minus ERFari in the IPCC AR5 case (Myhre et al. 2013), was estimated to be -0.45 (- 1.2 to 0.0$) \mathrm{W} \mathrm{m}^{-2}$. Zelinka et al. (2014) conducted a systematic intercomparison of ERFs across the fifth phase of the Coupled Model Intercomparison Project (CMIP5) models. The present-day (year 2000) net ERFari+aci was estimated to be $-1.17 \pm$ $0.30 \mathrm{~W} \mathrm{~m}^{-2}$, consisting of an ERFari of $-0.25 \pm 0.22 \mathrm{~W}$ $\mathrm{m}^{-2}$ and an ERFaci of $-0.92 \pm 0.34 \mathrm{~W} \mathrm{~m}^{-2}$. The large intermodel spread in the ERFaci values was dominated by differences among models in how the aerosols affected the cloud albedo (Zelinka et al. 2014). Previous studies have indicated that aerosols and clouds are still the largest source of uncertainty in estimates of radiative forcing of the climate (Boucher et al. 2013), and further improvements to aerosol and cloud processes in models are required from CMIP5.

Recently, we developed the Meteorological Research Institute Earth System Model version 2.0 (MRI-ESM2.0; Yukimoto et al. 2019) as a major update of our previous MRI coupled global climate model version 3, MRICGCM3 (Yukimoto et al. 2012), which participated in CMIP5 (Taylor et al. 2012). We implemented multiple modifications in the model with particular emphasis on improving the aerosol and cloud processes (Yukimoto et al. 2019; Kawai et al. 2019). For example, significant improvements to the cloud representations in MRIESM2.0 led to a remarkable reduction in errors in the SW, LW, and net radiation at the TOA, and the score of the spatial pattern of the radiative fluxes at the TOA for MRI-ESM2.0 is better than the 48 CMIP5 models (Kawai et al. 2019). MRI-ESM2.0 participated in the sixth phase of CMIP (CMIP6; Eyring et al. 2016). To estimate ERF and quantify the climate impacts of anthropogenic gases and aerosols using MRI-ESM2.0, we participate in the Radiative Forcing Model Intercomparison Project (RFMIP; Pincus et al. 2016) and the Aerosol and Chemistry Model Intercomparison Project (AerChemMIP; Collins et al. 2017), which are endorsed by CMIP6.

In this study, we perform all time-slice perturbation experiments from the anthropogenic forcing agents planned in RFMIP and AerChemMIP using MRIESM2.0, which enables a comprehensive estimation of the present-day ERFs from individual anthropogenic agents in a consistent manner with the same physical and chemical processes in the model (e.g., the model including the aerosol effects on ice clouds). We estimate the global mean SW, LW, and net ERFs induced by all anthropogenic agents, including well-mixed greenhouse gases, short-lived gases, aerosols and their precursors, and land use. Particularly, we focus on the role of aerosols and quantify the contributions to the aerosol ERFs from aerosol-radiation interactions (ARI), aerosol-cloud interactions (ACI), and changes in the surface albedo due to the aerosols. The ERF estimations are also 
conducted over the Arctic. In addition, we compare the aerosol ERF estimates to those derived using different diagnostic approaches and those calculated by our previous model and other CMIP6 models.

\section{Methods \\ Models}

We use MRI-ESM2.0 to estimate present-day ERFs due to anthropogenic forcing agents. Detailed descriptions and evaluations of MRI-ESM2.0 are given by Yukimoto et al. (2019). Brief descriptions of the model and the processes related to this study are given below.

MRI-ESM2.0 consists of four major component models: an atmospheric general circulation model with land processes (MRI-AGCM3.5), an ocean-sea-ice general circulation model (OGCM), an aerosol chemical transport model, and an atmospheric chemistry model; however, we do not couple OGCM in this study. MRIESM2.0 uses different horizontal resolutions in each atmospheric component model but employs the same vertical resolution, i.e., TL159 (approximately $120 \mathrm{~km}$ ), TL95 (approximately $180 \mathrm{~km}$ ), and T42 (approximately $280 \mathrm{~km}$ ) are used in MRI-AGCM3.5, the aerosol chemical transport model, and the atmospheric chemistry model, respectively; all models employ 80 vertical layers (from the surface to the model top at $0.01 \mathrm{hPa}$ ) in a hybrid sigma-pressure coordinate system. A coupler (Yoshimura and Yukimoto 2008) is used to interactively couple each component model in MRI-ESM2.0; this enables an explicit representation of the effects of the gases and aerosols on the climate system (e.g., the interactions of aerosols with radiation, clouds, and the surface albedo of snow and ice).

The atmospheric chemistry component model used in MRI-ESM2.0 is the MRI Chemistry Climate Model version 2.1 (MRI-CCM2.1), which calculates evolution and distribution of the ozone and other trace gases in the troposphere and middle atmosphere. The model calculates a total of 90 gas-phase chemical species and 259 chemical reactions in the atmosphere. The chemical reactions of well-mixed greenhouse gases $\left(\mathrm{CO}_{2}, \mathrm{CH}_{4}\right.$, $\mathrm{N}_{2} \mathrm{O}$, and halocarbons) are treated in MRI-CCM2.1; however, MRI-CCM2.1 does not provide the concentrations of these species to MRI-AGCM3.5, which calculates the radiative effects of the greenhouse gases according to the concentrations given by the boundary conditions. Although sulfur chemistry is not treated in MRI-CCM2.1, the chemical species required for sulfur chemistry (e.g., ozone, hydrogen oxide radicals $\left(\mathrm{HO}_{\mathrm{x}}\right)$ and hydrogen peroxide $\left(\mathrm{H}_{2} \mathrm{O}_{2}\right)$ ) are provided from MRICCM2.1 to the aerosol component model. The aerosol component model used in MRI-ESM2.0 is the Model of Aerosol Species in the Global Atmosphere mark-2 revision 4-climate (MASINGAR mk-2r4c), which calculates the physical and chemical processes (e.g., emission, transport, diffusion, chemical reactions, and dry and wet depositions) of the atmospheric aerosols and treats the following species: non-sea-salt sulfate, $\mathrm{BC}$, organic carbon (OC), sea salt, mineral dust, and aerosol precursor gases (e.g., sulfur dioxide $\left(\mathrm{SO}_{2}\right)$ and dimethyl sulfide). The size distributions of sea salt and mineral dust are divided into 10 discrete bins, while the sizes of the other aerosols are represented by lognormal size distributions. The model assumes external mixing for all aerosol species; however, in the radiation process in MRIAGCM3.5, it is assumed that hydrophilic BC is internally mixed with sulfate with a shell-to-core volume ratio of 2 , and the optical properties of hydrophilic BC are calculated based on Mie theory with a core-shell aerosol treatment, in which a concentric BC core is surrounded by a uniform coating shell composed of other aerosol compounds (Oshima et al. 2009a, 2009b). MRI-ESM2.0 employs a BC aging parameterization (Oshima and Koike 2013) that calculates the variable conversion rate of $\mathrm{BC}$ from hydrophobic $\mathrm{BC}$ to hydrophilic $\mathrm{BC}$, in which the conversion rate generally depends on production rate of condensable materials such as sulfate. Note that the $\mathrm{BC}$ aging parameterization implementation could reproduce seasonal variations of the $\mathrm{BC}$ mass concentrations observed over the Arctic (Mori et al. submitted; Koike et al. submitted; Oshima et al. in preparation). The deposition fluxes of $\mathrm{BC}$ and mineral dust calculated in the aerosol component model are provided to a physically based snow albedo model in MRI-AGCM3.5, which calculates the broadband albedos and the solar heating profile in the snowpack as functions of the snow grain size and concentrations of snow impurities (Aoki et al. 2011). In the radiation and cloud processes in MRI-ESM2.0, sulfate is assumed to be $\left(\mathrm{NH}_{4}\right)_{2} \mathrm{SO}_{4}$, and $\mathrm{OC}$ is assumed to be organic matter $(\mathrm{OM})$ by lumping $\mathrm{OC}$ species using an OM-to-OC factor of 1.4.

MRI-ESM2.0 represents the activation of aerosols into cloud droplets based on the parameterizations of AbdulRazzak et al. (1998), Abdul-Razzak and Ghan (2000), and Takemura et al. (2005). For the temperature range from - 38 to $0{ }^{\circ} \mathrm{C}$, the deposition nucleation is calculated based on the study of Meyers et al. (1992), and the immersion and condensation freezing are calculated based on the studies of Bigg (1953), Murakami (1990), Levkov et al. (1992), and Lohmann (2002). In these parameterizations, the aerosol concentrations are not explicitly considered. Therefore, in this temperature range, aerosol concentrations do not directly affect the number concentrations of the ice crystals in the model except in the case of contact freezing (Lohmann and Diehl 2006; Cotton et al. 1986). Ice nucleation for cirrus clouds is represented using a parameterization from Kärcher et al. (2006), when the temperature is less than $-38{ }^{\circ} \mathrm{C}$; 
homogeneous nucleation (Kärcher and Lohmann 2002) for sulfate, $\mathrm{OM}$, and sea salt aerosols and heterogeneous nucleation (Kärcher and Lohmann 2003) for BC and mineral dust aerosols. Although aerosol-cloud interactions in anvil clouds are considered, the interactions within the cores of convections are not incorporated (i.e., aerosol-cloud interactions are not calculated in the convection scheme). The updraft velocities that are used for the aerosol activations are represented as the sum of the grid-scale vertical velocity and the velocity fluctuations due to turbulence, which can be obtained from a turbulence scheme (e.g., Lohmann et al. 1999; Takemura et al. 2005) (note that a lower limit of $0.12 \mathrm{~m} \mathrm{~s}^{-1}$ is set for the velocity fluctuations). More detailed descriptions and evaluations of the cloud processes and cloud representations in MRI-ESM2.0 are given by Kawai et al. (2019).

We compare the results calculated by our previous model, MRI-CGCM3, in the CMIP5 experiments to those obtained by MRI-ESM2.0 in this study. Details concerning MRI-CGCM3 and the evaluations are given by Yukimoto et al. (2012). MRI-CGCM3 is a previous version of MRI-ESM2.0, and the basic framework (e.g., interactive coupled system of each component model by the coupler and the horizontal resolutions of each component model) of the two models are the same, although there are major updates to multiple components of MRI-ESM2.0 (Yukimoto et al. 2019; Kawai et al. 2019). The major differences in the framework of the two models are that MRI-CGCM3 employed 48 vertical layers and that the atmospheric chemistry component model was not coupled in MRI-CGCM3 in the CMIP5 experiments.

\section{Model experiments}

We perform 31-year time-slice experiments with the prescribed preindustrial climatology of sea surface temperature (SST) and sea ice using MRI-ESM2.0 within the frameworks of RFMIP (Pincus et al. 2016) and AerChemMIP (Collins et al. 2017) as summarized in Table 1. The monthly climatology of the SST and sea ice data were taken from the 500-year average of those calculated in the preindustrial control (piControl, one of the Diagnostic, Evaluation, and Characterization of Klima (DECK) experiments in CMIP6) experiment conducted by the atmosphere-ocean-chemistry-aerosol coupled version of MRIESM2.0. A detailed description of the piControl experiment performed by MRI-ESM2.0 is given by Yukimoto et al. (2019).

The control simulation (piClim-control experiment) is performed for 31-year time slices with the preindustrial (year 1850) conditions of well-mixed greenhouse gas concentrations, short-lived gas and aerosol emissions, and land use in the prescribed preindustrial SST and sea ice configurations (Table 1). The piClim-control experiment serves as a baseline for estimations of the ERFs in this study. The piClim-control experiment is initiated

Table 1 Summary of the experiments performed by MRI-ESM2.0

\begin{tabular}{|c|c|c|c|c|c|c|c|c|c|c|c|}
\hline \multirow[t]{2}{*}{ Experiment name } & \multicolumn{10}{|c|}{ Anthropogenic emissions and drivers } & \multirow[t]{2}{*}{ MIP name } \\
\hline & $\mathrm{CO}_{2}$ & $\mathrm{CH}_{4}$ & $\mathrm{CFC} / \mathrm{HCFC}$ & $\mathrm{N}_{2} \mathrm{O}$ & CONOC & $\mathrm{NOx}$ & $\mathrm{BC}$ & $\mathrm{OC}$ & $\mathrm{SO}_{2}$ & Land Use & \\
\hline piClim-control & & & & & & & & & & & RFMIP/AerChemMIP \\
\hline piClim-ghg & 2014 & 2014 & 2014 & 2014 & & & & & & & RFMIP \\
\hline piClim-4xCO2 $2^{a}$ & $4 \times C O 2(1850)$ & & & & & & & & & & RFMIP \\
\hline piClim-CH4 & & 2014 & & & & & & & & & AerChemMIP \\
\hline piClim-HC & & & 2014 & & & & & & & & AerChemMIP \\
\hline piClim-N2O & & & & 2014 & & & & & & & AerChemMIP \\
\hline piClim-VOC & & & & & 2014 & & & & & & AerChemMIP \\
\hline piClim-NOx & & & & & & 2014 & & & & & AerChemMIP \\
\hline piClim-O3 & & & & & 2014 & 2014 & & & & & AerChemMIP \\
\hline piClim-NTCF & & & & & 2014 & 2014 & 2014 & 2014 & 2014 & & AerChemMIP \\
\hline piClim-aer & & & & & & & 2014 & 2014 & 2014 & & RFMIP/AerChemMIP \\
\hline piClim-BC & & & & & & & 2014 & & & & AerChemMIP \\
\hline piClim-OC & & & & & & & & 2014 & & & AerChemMIP \\
\hline piClim-SO2 & & & & & & & & & 2014 & & AerChemMIP \\
\hline piClim-lu & & & & & & & & & & 2014 & RFMIP \\
\hline piClim-anthro & 2014 & 2014 & 2014 & 2014 & 2014 & 2014 & 2014 & 2014 & 2014 & 2014 & RFMIP \\
\hline
\end{tabular}

Blank spaces in the table indicate the preindustrial conditions for the year 1850 . The values " 2014 " in the table indicate the present-day conditions for the year 2014

${ }^{a}$ Carbon dioxide concentrations in the piClim-4xCO2 experiment are set to four times the preindustrial values for the year 1850 
from the output of a 10-year spin-up run with the same preindustrial conditions.

A series of perturbation experiments is performed for each 31-year time slice using the same prescribed preindustrial SST and sea ice conditions but with the presentday (year 2014) conditions for each species as follows: present-day well-mixed greenhouse gas concentrations (piClim-ghg), four times the preindustrial $\mathrm{CO}_{2}$ concentrations (piClim-4xCO2), present-day $\mathrm{CH}_{4}$ concentrations (piClim-CH4), present-day chlorofluorocarbons (CFCs) and hydrochlorofluorocarbon (HCFC) concentrations (piClim-HC), present-day $\mathrm{N}_{2} \mathrm{O}$ concentrations (piClim-N2O), present-day carbon monoxide $(\mathrm{CO})$ and volatile organic compound (VOC) emissions (piClim$\mathrm{VOC}$ ), present-day nitrogen oxide (NOx) emissions (piClim-NOx), present-day $\mathrm{CO} / \mathrm{VOC} / \mathrm{NOx}$ emissions (piClim-O3), present-day emissions of near-term climate forcers (NTCFs, i.e., tropospheric ozone and aerosols and their precursors, not including methane here) (piClim-NTCF); present-day $\mathrm{BC} / \mathrm{OC} / \mathrm{SO}_{2}$ emissions (piClim-aer); present-day BC emissions (piClim-BC); present-day $\mathrm{OC}$ emissions (piClim-OC); present-day $\mathrm{SO}_{2}$ emissions (piClim-SO2); present-day land use (piClim-lu); and all present-day anthropogenic forcers (piClim-anthro) as summarized in Table 1. The output of the 10-year spin-up run for the piClim-control experiment is used as the initial state for these perturbation experiments, except for the $\mathrm{CH}_{4}, \mathrm{HC}$, and $\mathrm{N}_{2} \mathrm{O}$ cases, which use the outputs of 10-year spin-up runs performed with their respective conditions. Note that the chemical species required for the production reactions of sulfate (e.g., $\mathrm{HO}_{\mathrm{x}}, \mathrm{H}_{2} \mathrm{O}_{2}$, and ozone) are calculated under the preindustrial conditions for the piClim-SO2 and piClim-aer experiments due to the experimental configuration.

We use the results from the 30-year prescribed SST and sea ice experiments by MRI-CGCM3 conducted as part of CMIP5 (Taylor et al. 2012) in this study. The control run (sstClim experiment) was performed for 30year time slices with the prescribed preindustrial climatology of the SSTs and sea ice derived from the preindustrial control run by MRI-CGCM3 in the CMIP5 preindustrial (year 1850) conditions. The perturbation run (sstClimAerosol experiment) was identical to that in the sstClim experiment but used the emissions of the anthropogenic aerosols and their precursors at year 2000 from the CMIP5 historical experiment.

\section{ERF estimates and decomposition into $\mathrm{ARI}, \mathrm{ACl}$, and surface albedo effects}

We use the last 30 years of each experiment for the analysis in this study. The ERFs at the TOA are calculated as the differences of the 30-year annual mean net (downward minus upward) TOA radiative fluxes between the perturbation experiment (present-day conditions) and the piClim-control experiment (preindustrial conditions). The signs of the radiative fluxes are defined as downward positive in this study. Although ERFs are generally defined at the TOA, we also estimate the ERFs at the surface, and these values denote the surface radiative flux changes between the perturbed and control experiments. Note that the changes in the surface latent and sensible heat fluxes are not regarded as part of the forcing in this study, although they may significantly impact the surface temperature response. The ERFs for the present-day $\mathrm{CO}_{2}\left(\Delta \mathrm{F}_{\mathrm{CO} 2}\right)$ are obtained from the results of the piClim- $4 \mathrm{xCO} 2$ experiment using the following approximation (Ramaswamy et al. 2001):

$$
\Delta \mathrm{F}_{\mathrm{CO} 2}=\Delta \mathrm{F}_{4 \times \mathrm{CO} 2} \ln \left(C / C_{0}\right) / \ln (4),
$$

where $C$ and $C_{0}$ are the $\mathrm{CO}_{2}$ concentrations at the present and preindustrial levels, respectively, and $\Delta \mathrm{F}_{4 \mathrm{xCO} 2}$ is the radiative flux difference between the piClim-4xCO2 experiment and the piClim-control experiment.

The aerosol ERF can be separated into forcings due to the aerosol-radiation interactions, aerosol-cloud interactions, and changes in the surface albedo due to aerosols. A direct method is proposed by Ghan (2013), which requires additional aerosol-free radiation calls in the model, to calculate these forcing components. We perform the aerosol-free radiation calls in MRI-ESM2.0 to diagnose the instantaneous radiative forcing of the aerosols in the experiments related to the aerosols. In this study, we employ the method of Ghan (2013) to decompose the ERFs at the TOA into aerosol-radiation interactions (ERFari), aerosol-cloud interactions (ERFaci), and surface albedo effects (ERFalbedo) as follows:

$$
\begin{aligned}
& \text { ERFari }=\Delta(F-\text { Faf }), \\
& \text { ERFaci }=\Delta(\text { Faf }- \text { Fcsaf }), \\
& \text { ERFalbedo }=\Delta \text { Fcsaf },
\end{aligned}
$$

where $F$ is the net radiative flux, Faf is the flux calculated neglecting the scattering and absorption of radiation by aerosols, Fcsaf is the flux calculated neglecting the scattering and absorption of radiation by both clouds and aerosols, and $\Delta$ indicates the difference between the perturbation experiment and the piClim-control experiment (af indicates aerosol-free and cs indicates clear-sky). This approach is applied to both the SW and LW radiation.

The approximate partial radiative perturbation (APRP) method can also decompose the ERFs into ARI, ACI, and surface albedo effects (Taylor et al. 2007; Zelinka et al. 2014). The APRP method can diagnose the ERF components using standard model outputs in climate models and can easily be employed in multi-model 
comparisons, although this method is approximate and may induce biases in the SW ERFs due to the ARI and ACI (Zelinka et al. 2014). We compare the decompositions of the aerosol radiative effects derived using the method of Ghan (2013) and the APRP method of Taylor et al. (2007).

\section{Results and discussion Global ERFs}

Figure 1 shows a summary of the global mean net ERF estimates at the TOA induced by the anthropogenic forcing agents (in year 2014 relative to year 1850). The ERF induced by the total anthropogenic components is estimated to be $1.96 \mathrm{~W} \mathrm{~m}^{-2}$, composed of a positive ERF due to the well-mixed greenhouse gases $\left(3.02 \mathrm{~W} \mathrm{~m}^{-2}\right)$, negative ERFs due to the NTCFs $\left(-1.08 \mathrm{~W} \mathrm{~m}^{-2}\right)$, which are mostly due to aerosols $\left(-1.22 \mathrm{~W} \mathrm{~m}^{-2}\right)$, and slightly negative ERFs due to land-use changes $\left(-0.19 \mathrm{~W} \mathrm{~m}^{-2}\right)$. In comparison to the best ERF estimates in IPCC AR5 (in year 2011 relative to year 1750), the ERF estimates by MRI-ESM2.0 in this study show lower total anthropogenic ERF by $0.33 \mathrm{~W} \mathrm{~m}^{-2}$ and more negative total aerosol ERF by $0.4 \mathrm{~W} \mathrm{~m}^{-2}$. In the following, we focus on the influences of anthropogenic gases and aerosols on the ERFs.

\section{Well-mixed greenhouse gases and short-lived gases}

Figure 2 shows the global mean LW and SW ERFs and their net values at the TOA as estimated by each experiment. The global mean ERF values at the TOA and at the surface are also summarized in Table 2. The net ERFs at the TOA from the well-mixed greenhouse gases are all positive, i.e., $1.85 \mathrm{~W} \mathrm{~m}^{-2}$ for $\mathrm{CO}_{2}, 0.71 \mathrm{~W} \mathrm{~m}^{-2}$ for $\mathrm{CH}_{4}, 0.30 \mathrm{~W} \mathrm{~m}^{-2}$ for halocarbons, and $0.16 \mathrm{~W} \mathrm{~m}^{-2}$ for $\mathrm{N}_{2} \mathrm{O}$ (Figs. 1 and 2). These forcings are dominated by LW radiation due to greenhouse effects; approximately $80 \% \mathrm{LW}$ and $20 \% \mathrm{SW}$ contributions are seen for the net ERFs of the total well-mixed greenhouse gases (Fig. 2). Note that the negative SW ERF value from halocarbons is primarily due to the decrease in the absorption of solar radiation due to halocarbon-induced stratospheric ozone depletion.

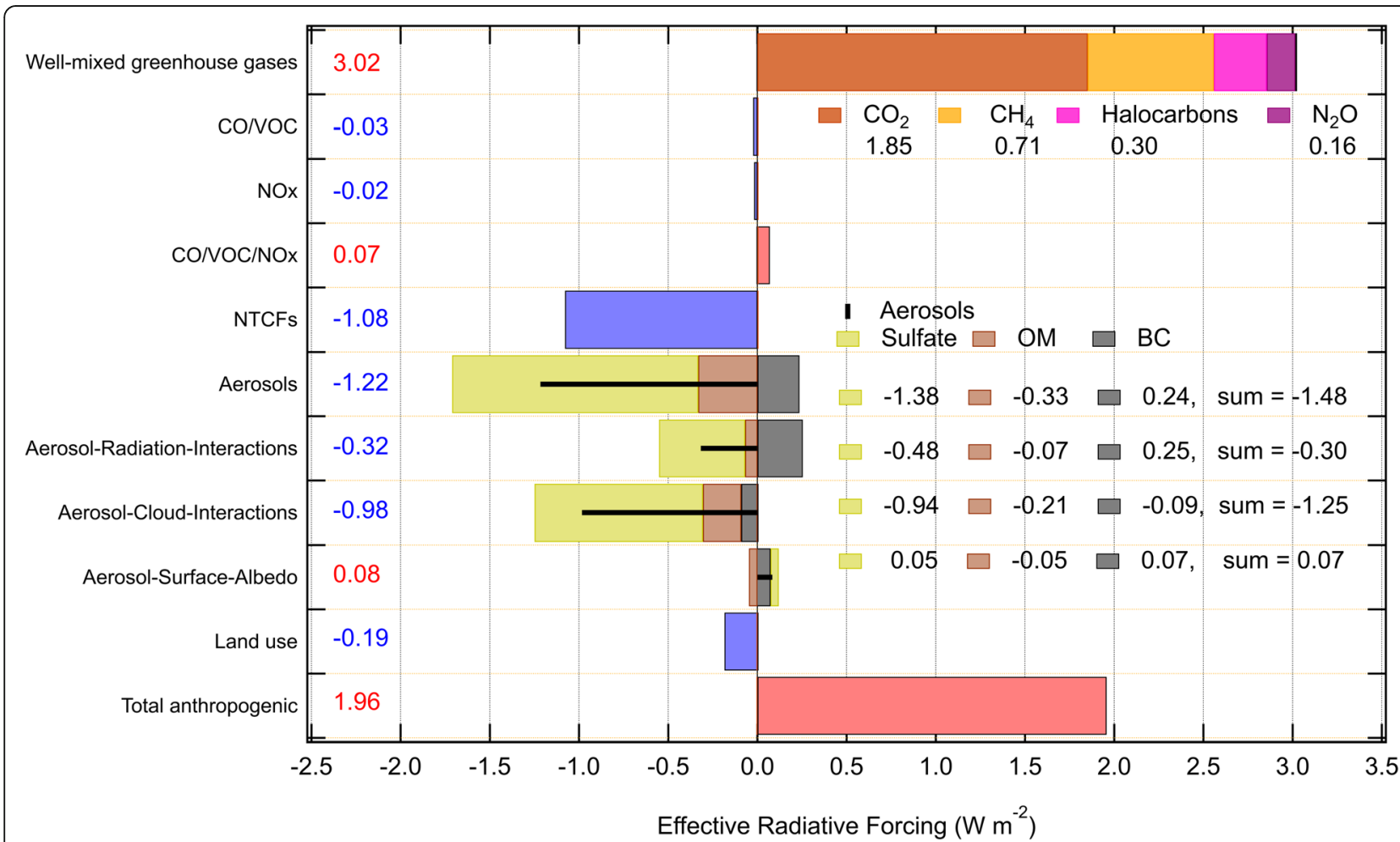

Fig. 1 Summary of the effective radiative forcing (ERF) estimates in the year 2014 relative to the year 1850 in MRI-ESM2.0. The estimates are the global annual mean net ERF values at the top of the atmosphere (TOA) caused by the emitted compounds and processes. The ERFs due to aerosols are separated into three radiative effects as follows: aerosol-radiation interactions, aerosol-cloud interactions, and the surface albedo changes due to aerosols. The values of the net ERFs are also shown on the left side of the figure (positive and negative values are indicated by red and blue, respectively). The ERFs caused by individual species or their precursors are shown by color crossbars with their values (e.g., $\mathrm{CO}_{2,}$ $\mathrm{CH}_{4}$, halocarbons, $\mathrm{N}_{2} \mathrm{O}$, sulfate, $\mathrm{OM}$, and $\mathrm{BC}$ ). The ERFs from the total aerosols (estimated by the piClim-aer experiment) are shown by black bars and are not equal to the sum of the individual ERFs from each aerosol. The ERFs of the other compounds are shown by red (positive) and blue (negative) crossbars, respectively. Values are given in units of $\mathrm{W} \mathrm{m}^{-2}$ 


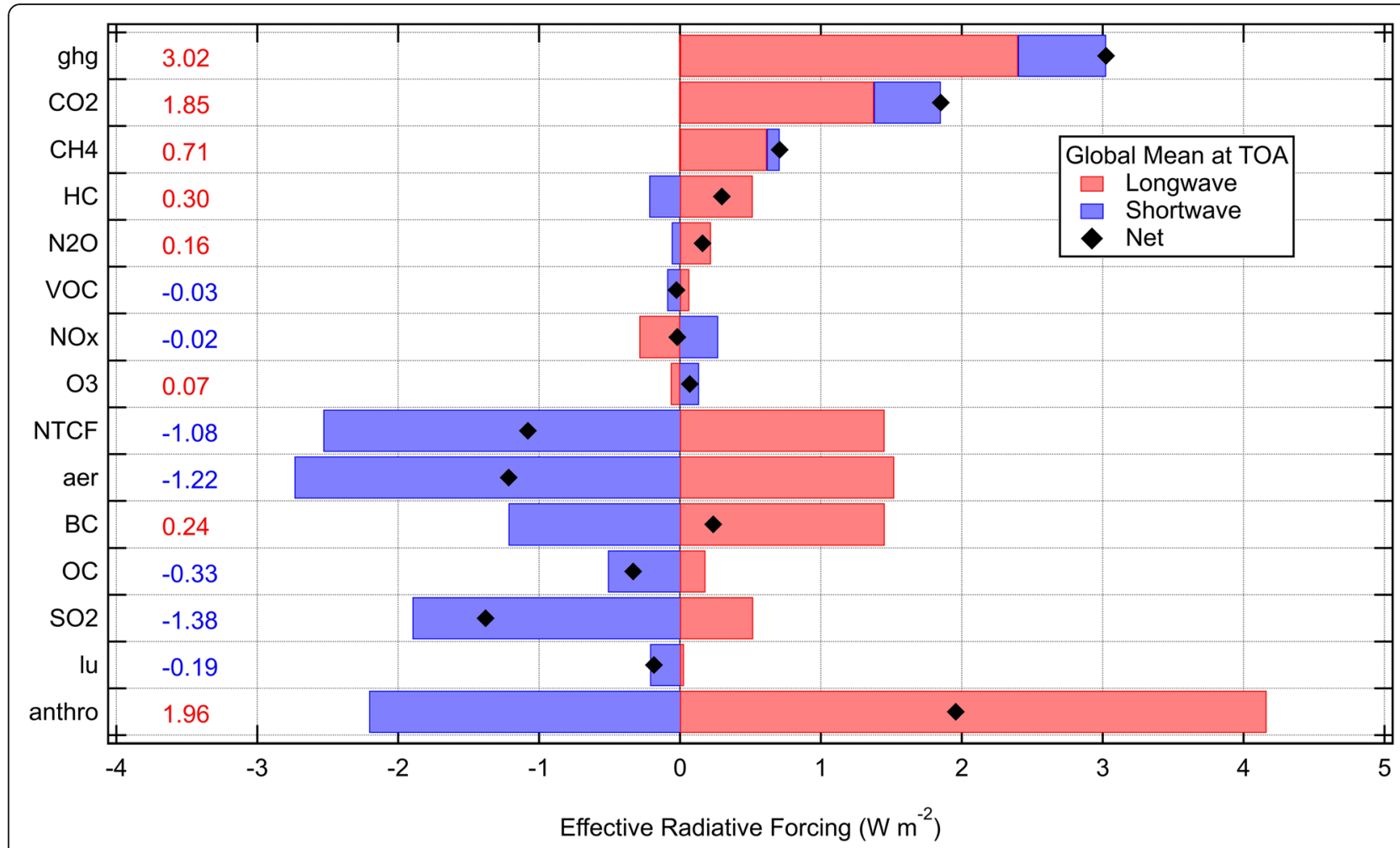

Fig. 2 Global and annual mean ERF estimates at the TOA in each experiment in MRI-ESM2.0. The longwave (red) and shortwave (blue) ERFs and the sum (net, black diamonds) are shown. The net ERF values are also shown on the left side of the figure (positive and negative values are indicated by red and blue, respectively) and are given in units of $\mathrm{W} \mathrm{m}^{-2}$. The experiment names are shown on the left axis. The ERFs from $\mathrm{CO}_{2}$ at present-day concentrations are estimated from the piClim-4xCO2 experiment. The ERF values are given in Table 2

The magnitudes of the global mean net ERFs of the short-lived gases, which are precursors of the tropospheric ozone, are small and exhibit both positive and negative signs, i.e., $-0.03 \mathrm{~W} \mathrm{~m}^{-2}$ for $\mathrm{CO} / \mathrm{VOC}$; -0.02 $\mathrm{W} \mathrm{m}{ }^{-2}$ for NOx; and $0.07 \mathrm{~W} \mathrm{~m}^{-2}$ for net $\mathrm{CO} / \mathrm{VOC} / \mathrm{NOx}$ (piClim-O3) (Figs. 1 and 2). Tropospheric ozone should enhance the greenhouse effect; however, the LW ERFs caused by $\mathrm{NOx}$ and $\mathrm{CO} / \mathrm{VOC} / \mathrm{NOx}$ are negative (Fig. 2 and Table 2). This result indicates that tropospheric ozone may influence clouds and convective activity, particularly over the tropics, and that the greenhouse effect of ozone can be masked by cloud changes, which complicates the net radiative effects. The changes in the atmospheric circulation caused by short-lived gases and aerosols are discussed in another paper (Deushi et al. in preparation).

\section{Aerosols}

The global mean net ERF estimate of the total aerosols at the TOA is $-1.22 \mathrm{~W} \mathrm{~m}^{-2}$ and is composed of positive forcing from $\mathrm{BC}\left(0.24 \mathrm{~W} \mathrm{~m}^{-2}\right)$ and negative forcings from sulfate $\left(-1.38 \mathrm{~W} \mathrm{~m}^{-2}\right)$ and $\mathrm{OM}\left(-0.33 \mathrm{~W} \mathrm{~m}^{-2}\right)$ (Fig. 1). The net ERF of the total aerosols is composed of partial offsets of the large negative SW and positive LW ERFs (Fig. 2). The net ERF of the total aerosols (-
$1.22 \mathrm{~W} \mathrm{~m}^{-2}$ ) consists of a $23 \%$ contribution from ARI ($\left.0.32 \mathrm{~W} \mathrm{~m}^{-2}\right)$, a $71 \%$ contribution from ACI $(-0.98 \mathrm{~W}$ $\mathrm{m}^{-2}$ ), and a small contribution from the surface albedo effect $\left(0.08 \mathrm{~W} \mathrm{~m}^{-2}\right)$ (Fig. 1), where these percentages are estimated using the absolute value of each effect.

Because aerosols are regionally distributed (Supplementary Fig. 1), the geographic distributions of the ERF are important. Figure 3 shows the spatial distributions of the SW, LW, and net ERFs at the TOA by the total aerosols and each aerosol species or precursor (e.g., $\mathrm{BC}, \mathrm{OC}$, and $\mathrm{SO}_{2}$ ). The SW ERF of the total aerosols (Fig. 3a) is generally negative and indicates strong forcing in the emission source regions and their downstream regions predominantly over the northern midlatitude, which is primarily due to the sulfate forcing (Fig. 3j). In addition, there is a strong negative SW ERF in the tropical convective regions. The LW ERF of the total aerosols (Fig. 3b) is generally positive and exhibits strong positive forcing in the tropical convective regions, particularly over the maritime continent via the eastern tropical Indian Ocean, where BC LW forcing (Fig. 3e) dominates the total aerosol LW ERF (Fig. 3b). In the following, we describe the ERF magnitudes and their spatial distributions by distinguishing the ARI, ACI, and surface albedo effects for the SW and LW radiation. 
Table 2 Global annual mean effective radiative forcings of each experiment

\begin{tabular}{|c|c|c|c|c|c|c|c|c|c|c|c|c|c|c|c|}
\hline \multirow[b]{2}{*}{ Experiment name } & \multicolumn{12}{|c|}{ ERF at TOA } & \multicolumn{3}{|l|}{ ERF at surface } \\
\hline & \multicolumn{4}{|l|}{ SW } & \multicolumn{4}{|l|}{ LW } & \multicolumn{4}{|l|}{ NET } & \multirow{2}{*}{$\frac{\text { SW }}{\text { Total }}$} & \multirow{2}{*}{$\begin{array}{l}\text { LW } \\
\text { Total }\end{array}$} & \multirow{2}{*}{$\begin{array}{l}\text { NET } \\
\text { Total }\end{array}$} \\
\hline & ARI & $\mathrm{ACl}$ & $A L B$ & Total & ARI & $\mathrm{ACl}$ & ALB & Total & ARI & $\mathrm{ACl}$ & ALB & Total & & & \\
\hline piClim-ghg & --- & --- & --- & 0.63 & --- & --- & --- & 2.40 & --- & --- & --- & 3.02 & -0.03 & 1.33 & 1.30 \\
\hline piClim-4xCO2 & --- & --- & --- & $1.97(0.48)$ & --- & --- & --- & $5.69(1.38)$ & -- & --- & --- & $7.66(1.85)$ & $-0.79(-0.19)$ & $3.36(0.81)$ & $2.57(0.62$ \\
\hline piClim-CH4 & --- & --- & --- & 0.09 & --- & --- & --- & 0.62 & --- & --- & --- & 0.71 & -0.06 & 0.33 & 0.27 \\
\hline piClim-HC & --- & --- & --- & -0.22 & --- & --- & --- & 0.52 & --- & --- & --- & 0.30 & 0.05 & 0.23 & 0.29 \\
\hline piClim-N2O & --- & --- & --- & -0.06 & --- & --- & --- & 0.22 & --- & --- & --- & 0.16 & 0.06 & 0.03 & 0.09 \\
\hline piClim-VOC & --- & --- & --- & -0.09 & -- & --- & -- & 0.07 & -- & --- & --- & -0.03 & -0.19 & 0.12 & -0.06 \\
\hline piClim-NOx & --- & --- & --- & 0.27 & --- & --- & --- & -0.29 & -- & --- & --- & -0.02 & -0.02 & 0.06 & 0.04 \\
\hline piClim-O3 & --- & --- & -- & 0.14 & --- & --- & --- & -0.07 & -- & --- & --- & 0.07 & -0.16 & 0.20 & 0.05 \\
\hline piClim-NTCF & --- & --- & --- & 2.53 & --- & --- & --- & 1.45 & --- & --- & --- & -1.08 & -3.39 & 0.87 & -2.52 \\
\hline piClim-aer & -0.32 & -2.47 & 0.05 & -2.74 & 0.00 & 1.49 & 0.03 & 1.52 & -0.32 & -0.98 & 0.08 & -1.22 & -3.26 & 0.68 & -2.57 \\
\hline piClim-BC & 0.26 & -1.63 & 0.15 & -1.22 & -0.00 & 1.54 & -0.08 & 1.45 & 0.25 & -0.09 & 0.07 & 0.24 & -1.95 & 0.78 & -1.17 \\
\hline piClim-OC & -0.07 & -0.43 & -0.02 & -0.52 & 0.00 & 0.21 & -0.03 & 0.18 & -0.07 & -0.21 & -0.05 & -0.33 & -0.52 & 0.05 & -0.47 \\
\hline piClim-SO2 & -0.49 & -1.36 & -0.05 & -1.90 & 0.00 & 0.42 & 0.09 & 0.52 & -0.48 & -0.94 & 0.05 & -1.38 & -1.77 & 0.21 & -1.56 \\
\hline piClim-lu & --- & --- & --- & -0.21 & -- & --- & -- & 0.03 & --- & --- & --- & -0.19 & -0.16 & -0.25 & -0.41 \\
\hline piClim-anthro & --- & --- & --- & -2.21 & --- & --- & -.- & 4.16 & -.- & --- & -.- & 1.96 & -3.56 & 2.01 & -1.56 \\
\hline
\end{tabular}

Values are given in units of $\mathrm{W} \mathrm{m}^{-2}$

$E R F$ effective radiative forcing, TOA top of the atmosphere, $S W$ shortwave, $L W$ longwave, $N E T S W+L W, A R I$ aerosol-radiation interactions, $A C l$ aerosol-cloud interactions, $A L B$ surface albedo effects, NTCF near-term climate forcers

${ }^{a}$ Values in parentheses are the ERFs of $\mathrm{CO}_{2}$ at present-day concentrations as estimated from the piClim- $4 \times \mathrm{CO} 2$ experiment

(a) ARI Figure 4 shows the spatial distributions of the SW ERFs at the TOA due to the ARI, ACI, and surface albedo effects for the total aerosols and each species using the method of Ghan (2013). Figures 5 and 6 show the spatial distributions of the aerosol ERFs at the TOA due to the ARI, ACI, and surface albedo effects for the LW and net radiation, respectively. The global mean SW, LW, and net ERFs of the aerosols due to each of the three components are summarized in Table 2. The SW ERFari values due to the total aerosols are mostly negative, particularly over the source regions (e.g., East Asia and South Asia; Fig. 4a and Supplementary Fig. 1a). $\mathrm{BC}$ aerosols efficiently absorb solar radiation and cause globally positive ERFs and largely positive ERFs over the source regions (Fig. 4d and Supplementary Fig. 1b). The ERFs of the scattering aerosols are globally negative and are largely negative over the source regions, particularly for sulfate (Fig. $4 \mathrm{~g}$ and $\mathrm{j}$ ). The smaller magnitude of the ERFs for OM compared to those for sulfate, which is consistent with the smaller aerosol optical depths of OM compared to those of sulfate (Supplementary Figs. 1c and $1 \mathrm{~d}$ ), is primarily due to the lower OC emission amounts, the lower hygroscopic growth of organic compounds, and the slight light-absorbing effects of $\mathrm{OC}$ as treated in the model based on recent observations and experiments (Yukimoto et al. 2019). The greater negative ERFs from the scattering effects compensate for the positive ERFs from light absorption, resulting in negative SW ERFari values for the total aerosols (Fig. 4a). The LW ERFari values of the aerosols are mostly negligible
(Table 2 and Fig. 5a, d, g, and j). As a result, the global mean net ERFari value at the TOA (Figs. 1 and 6) is estimated to be $-0.32 \mathrm{~W} \mathrm{~m}^{-2}$ for the total aerosols and consists of $\mathrm{BC}\left(0.25 \mathrm{~W} \mathrm{~m}^{-2}\right), \mathrm{OM}\left(-0.07 \mathrm{~W} \mathrm{~m}^{-2}\right)$, and sulfate $\left(-0.48 \mathrm{~W} \mathrm{~m}^{-2}\right)$ components, which comprise $23 \%$ of the net ERF from the total aerosols (Fig. 1).

(b) ACI and aerosol effects on high-level ice clouds The SW ERFs due to ACI from the total aerosols are globally negative and are substantially negative over the tropical convective regions (particularly over the maritime continent and the eastern Indian Ocean) and the source and downwind regions (Fig. 4b). The global mean SW ERFaci values of the individual aerosol species are all negative (Fig. 4e, h, and k) and contribute to the large negative ERFaci values of the total aerosols. Over the source and downwind regions, a large number of aerosols could influence clouds by serving as $\mathrm{CCN}$ and by increasing the cloud droplet number concentrations of liquid clouds (Supplementary Fig. 2). The SW ERFaci is dominated by sulfate, primarily due to higher $\mathrm{CCN}$ activity and greater sulfate amounts (Supplementary Fig. 1), rather than $\mathrm{BC}$ and $\mathrm{OM}$ (Fig. 4k). Over the tropical convective regions, $\mathrm{BC}$ aerosols are vertically transported into the upper troposphere by deep convection and serve as INPs at high altitude and influence ice clouds, resulting in substantially negative SW ERFaci values (Fig. 4e).

On the other hand, the LW ERFs due to ACI from the total aerosols are globally positive and are significantly positive over the tropical convective regions and over 

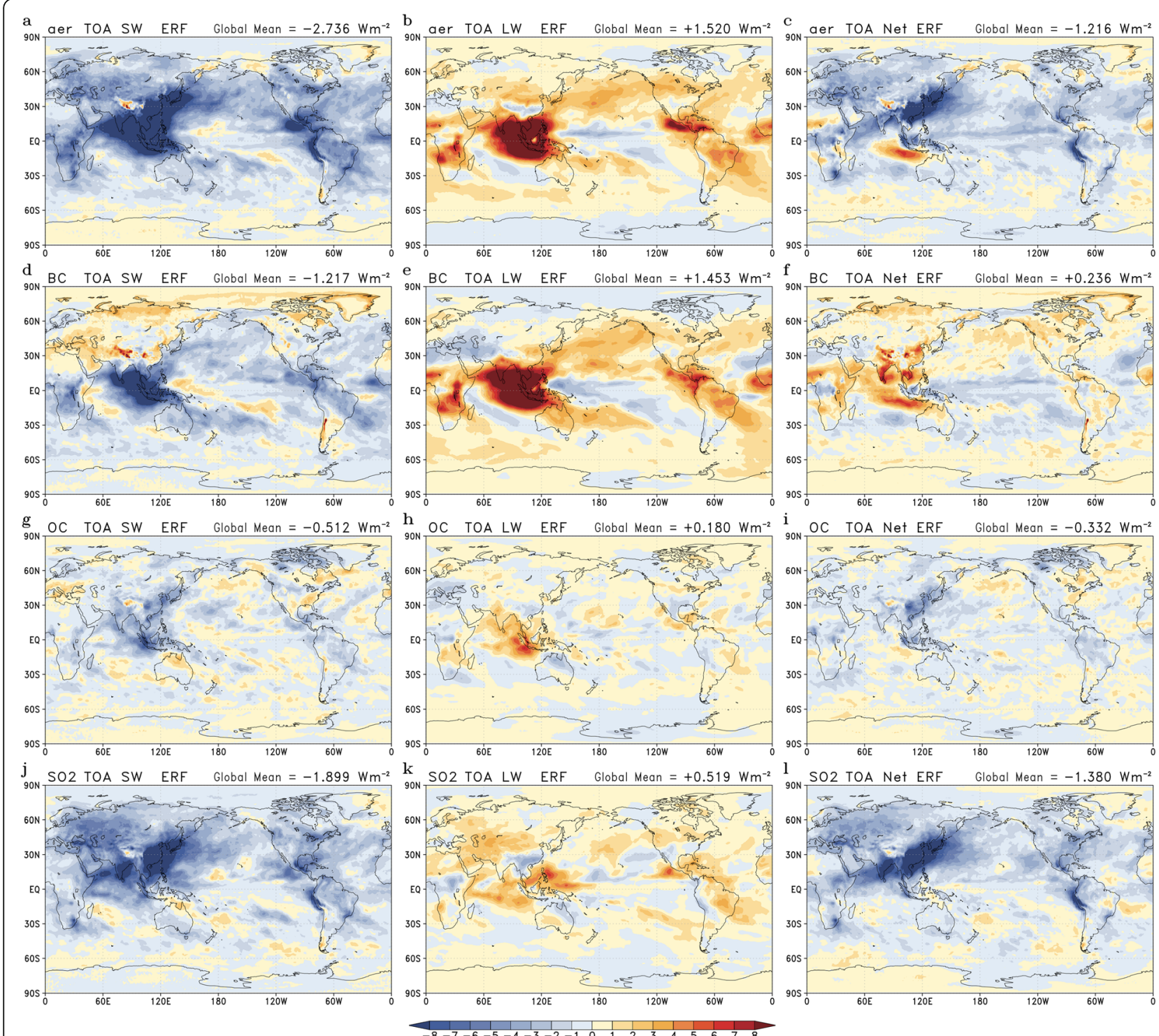

Fig. 3 Horizontal distributions of the annual mean ERFs (W m ${ }^{-2}$, filled contours) at the TOA for shortwave (SW, left); longwave (LW, middle); and their sum (net, right) in the (a-c) piClim-aer (aer); (d-f) piClim-BC (BC); (g-i) piClim-OC (OC); and (j-I) piClim-SO2 (SO2) experiments in MRIESM2.0. The global mean ERF values are shown near the upper-right corner of each panel and are given in Table 2

the oceans along storm tracks in the Northern Hemisphere (e.g., in the Pacific and Atlantic oceans) (Fig. 5b). In such regions, the influences of aerosols on high-level clouds, which have efficient greenhouse effects, are responsible for the positive LW ERFaci values. Positive LW ERFaci values are present for all aerosol species (Fig. 5e, h, and k) and are largest for $\mathrm{BC}$ (Fig. 5e). The LW ERFs at the TOA are mostly dominated by ACI (Fig. 5 and Table 2), leading to similar distributions between the total LW ERFs (Fig. 3b) and the LW ERFaci (Fig. 5b).

Here, we discuss the mechanism for the pronounced SW and LW ERFaci values over the tropical convective regions (Figs. $4 \mathrm{~b}$ and $5 \mathrm{~b}$ ). In terms of the $\mathrm{LW}$ radiation, increases in aerosols at high altitudes where high-level clouds are frequently present (i.e., regions with low outgoing LW radiation) are essential for the LW ERFaci, although one may simply consider that the impacts of aerosols on ERFaci depend only on the aerosol concentrations. Figure 7 shows the spatial distributions of the high-level cloud cover and the column-integrated number concentration of ice crystals in the piClim-aer experiment and the changes in the column-integrated number concentration of ice crystals due to the total aerosols. Note that the effects of the aerosols on the cloud cover, liquid water path, and ice water path are smaller than those on the number concentrations of the cloud droplets and ice crystals (Supplementary Figs. 2 and 3). The increases in the number concentrations of 


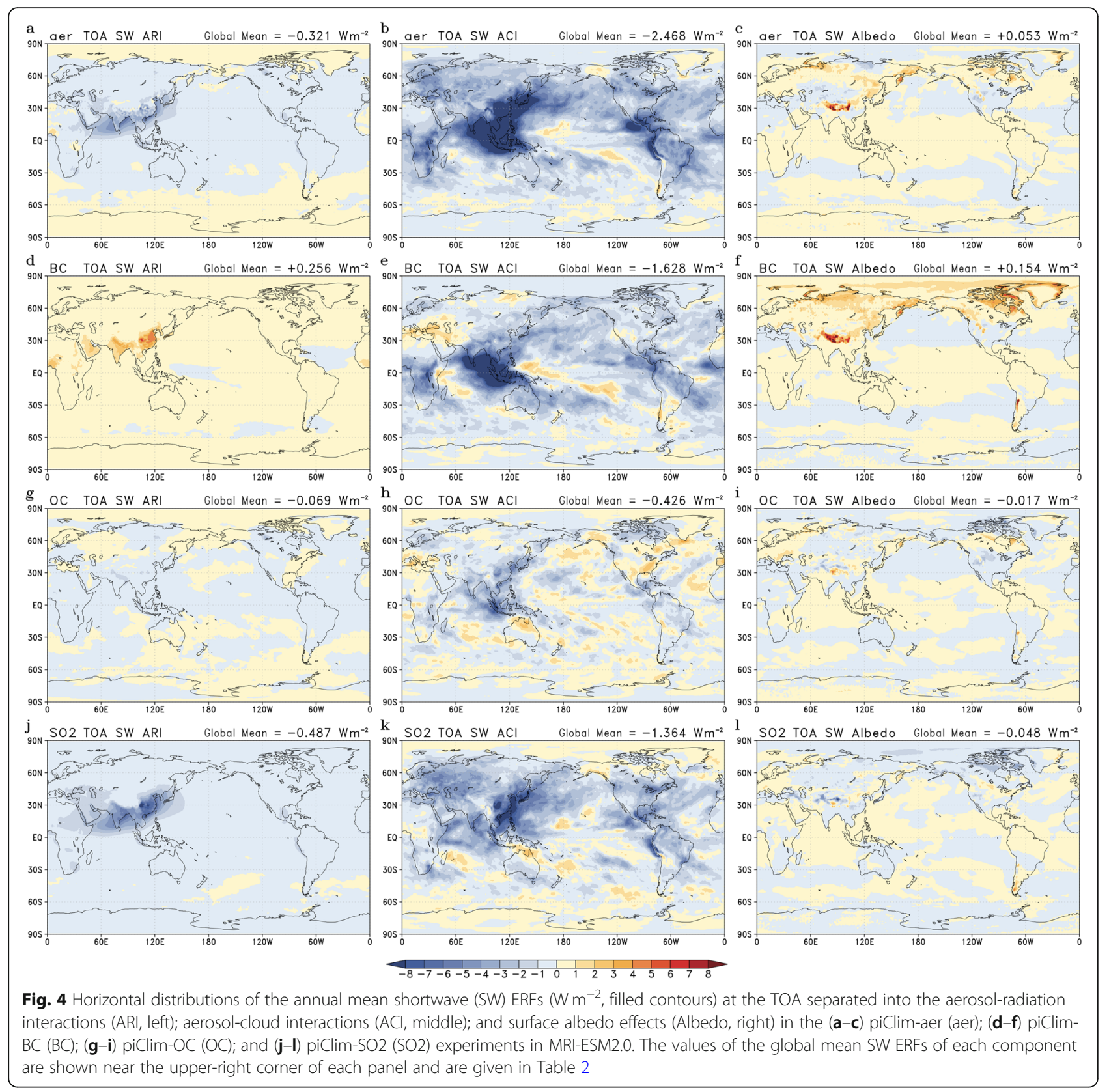

ice crystals due to the total aerosols are pronounced in the upper troposphere (Supplementary Fig. 4) at higher altitudes $(150-300 \mathrm{hPa})$ over the tropical convective regions (i.e., the maritime continent via the eastern tropical Indian Ocean and over central Africa) and at lower altitudes $(250-500 \mathrm{hPa})$ over the midlatitude Pacific along the storm tracks (Fig. 7c). The results clearly indicate that regions with pronounced LW ERFaci values (Fig. 5b) correspond to regions where both the number concentrations of ice crystals and the high-level cloud cover are large (Fig. 7). In the upper troposphere, the number concentrations of the total aerosols, which can contribute to the formation of ice clouds by serving as
INPs, increase over the source and downwind regions in the midlatitude Pacific and modestly increase over the tropical convective regions (Supplementary Figs. 5 and 6) due to the upward transport of aerosols by cyclones (which occur frequently in boreal winter and spring) and cumulus convections (in boreal summer). Note that the large aerosol number concentrations influenced by $\mathrm{BC}$ in the piClim-BC experiment (Supplementary Fig. 5b) are due to the smaller prescribed size distribution of $\mathrm{BC}$ compared to those of sulfate and OM in MRI-ESM2.0, as well as the nonlinear effects of $\mathrm{BC}$, as discussed below. In boreal summer, high-cloud regions (e.g., regions enclosed within the thick black lines in Supplementary Fig. 6) are 


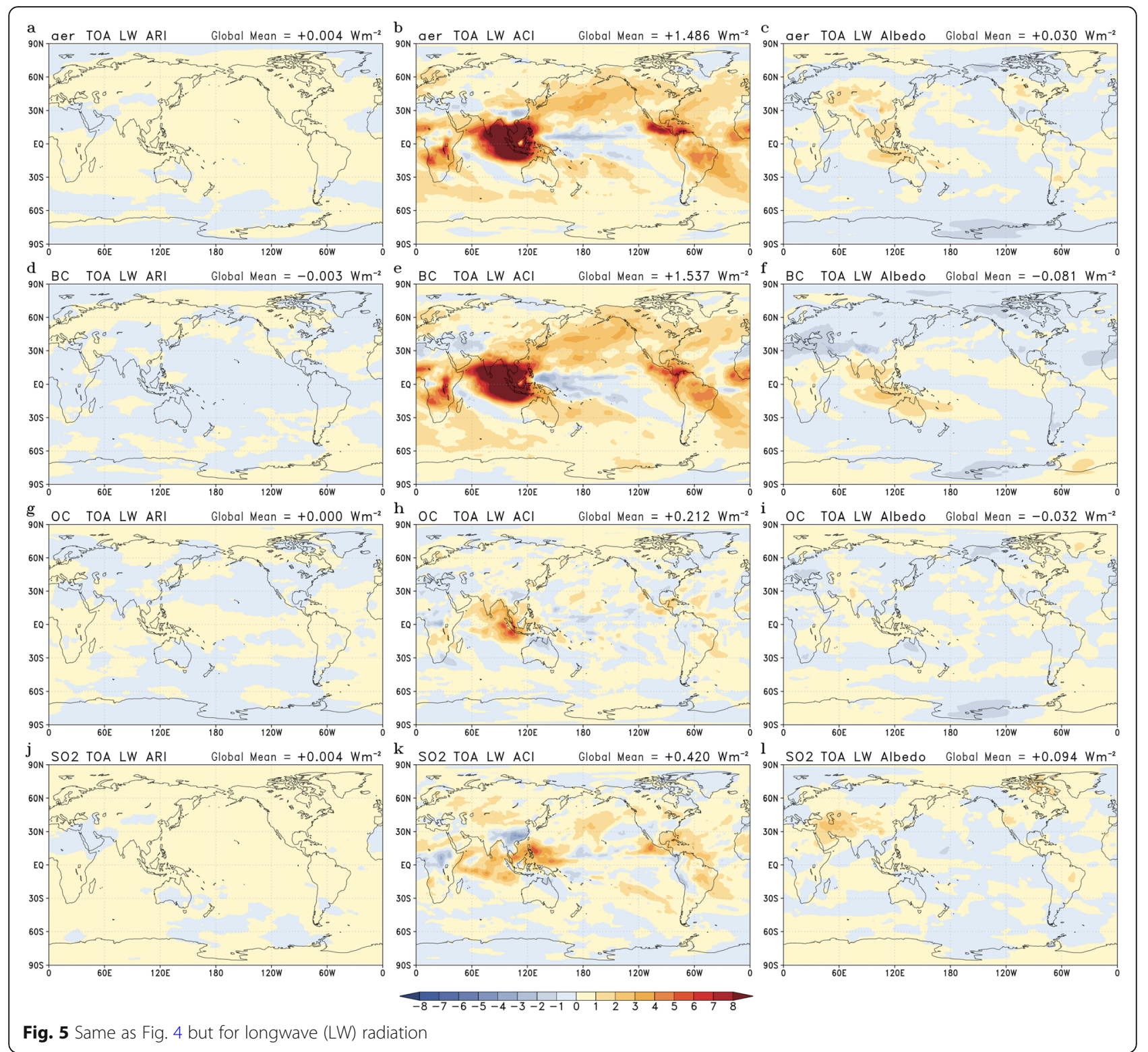

shifted north (i.e., close to the source regions) and partially overlap regions with large aerosol number concentrations, leading to increases in the number concentrations of ice crystals in the vicinity of the maritime continent and the eastern tropical Indian Ocean (Supplementary Fig. 7). However, despite the larger number concentrations of aerosols over the midlatitude regions, ice clouds over these regions are less effective for the LW radiation than those over tropical regions because the high-level cloud cover is smaller and the ice clouds are present at lower altitudes $(250-500 \mathrm{hPa})$ over the midlatitude regions. These mechanisms are responsible for the pronounced LW ERFaci over the tropical convective regions (Fig. 5). In terms of the SW radiation, anvil clouds generally have a similar magnitude of positive LW and negative SW cloud radiative effects due to reflection of the SW radiation, which leads to pronounced negative SW ERFaci values over the tropical convective regions (Figs. 4 and 5).

The significantly negative SW ERFaci values (Fig. 4b) and significantly positive LW ERFaci values (Fig. 5b) in the high-level clouds, which are particularly pronounced over the tropical convective regions, mostly cancel each other out. On the other hand, the negative SW ERFaci values in the low-level clouds (Fig. 4b) are unlikely to be offset by LW radiation (Fig. 5b), resulting in globally negative net ERFaci values (Fig. 6b), which are pronounced over the source and downwind regions. The global mean net ERFaci value at the TOA (Figs. 1 and 6) is estimated to be $-0.98 \mathrm{~W} \mathrm{~m}^{-2}$ for the total aerosols, consisting of $\mathrm{BC}\left(-0.09 \mathrm{~W} \mathrm{~m}^{-2}\right)$, OM $\left(-0.21 \mathrm{~W} \mathrm{~m}^{-2}\right)$, 


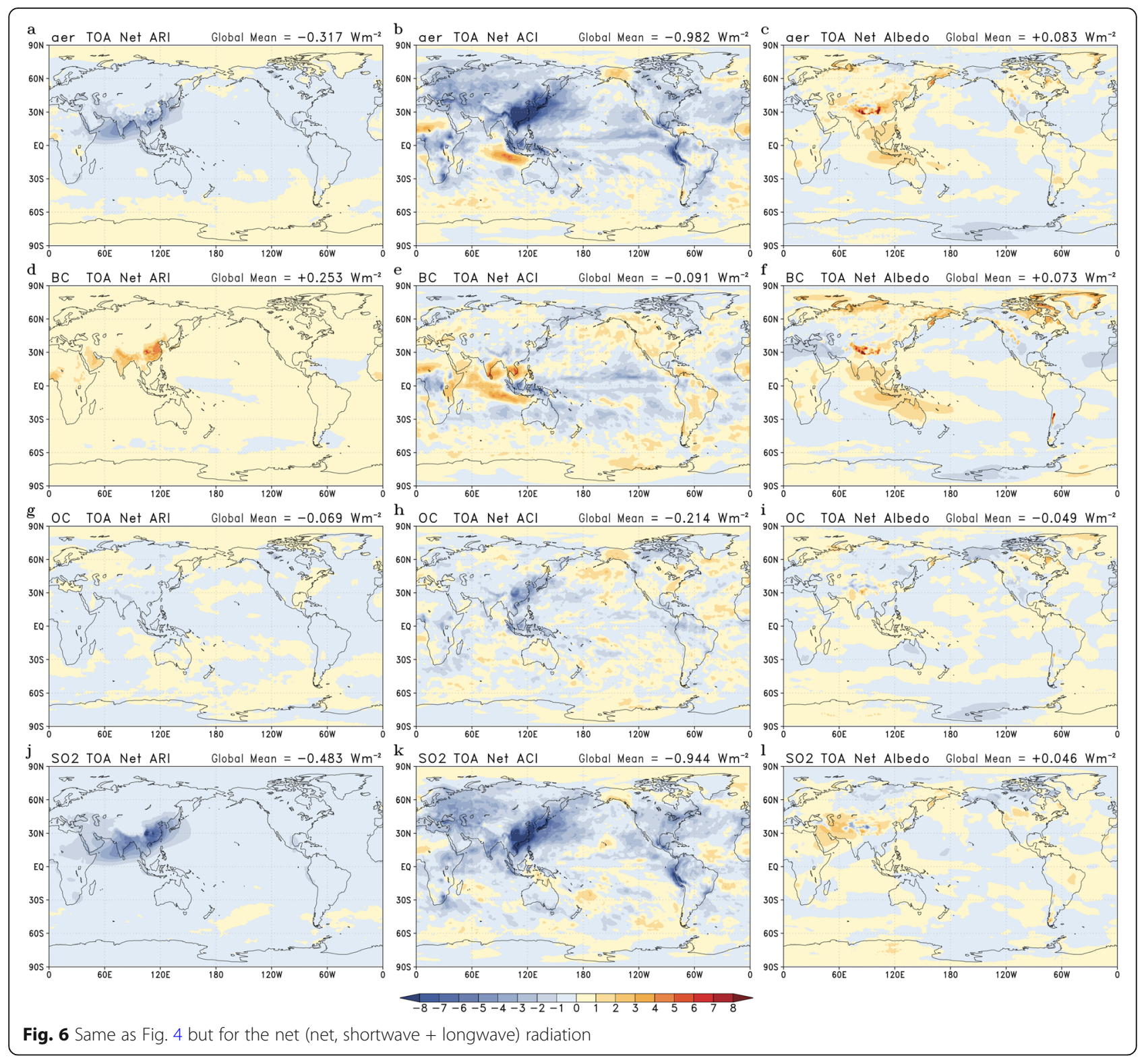

and sulfate $\left(-0.94 \mathrm{~W} \mathrm{~m}^{-2}\right)$ components, which account for $71 \%$ of the net ERF from the total aerosols (Fig. 1). Note that the sum of the ERFaci values for each aerosol compound $\left(-1.25 \mathrm{~W} \mathrm{~m}^{-2}\right)$ does not equal the ERFaci value for all the aerosols $\left(-0.98 \mathrm{~W} \mathrm{~m}^{-2}\right)$, as shown in Fig. 1, due to the strong nonlinearities in the ACI process. Carslaw et al. (2013) demonstrated that the sensitivity of the cloud albedo to anthropogenic emissions is much higher under preindustrial conditions (lower aerosol concentrations) than under present-day conditions (higher aerosol concentrations). The increase in the insensitivity of the cloud albedo with increasing emissions explains in part why the change in the indirect radiative forcing caused by the present-day emissions, with all species combined, is smaller than the sum of the forcings caused by the individual species.

Our results suggest that the interactions of the aerosols with ice clouds can cause both substantial SW and LW radiative forcing anomalies in MRI-ESM2.0. The parameterization of the interactions of the aerosols with ice clouds used in the model leads to INP production by the $\mathrm{BC}$ particles and influences the high-level clouds (temperatures $<-38^{\circ} \mathrm{C}$ ). Recent experimental studies suggest that $\mathrm{BC}$ particles are not as efficient for INPs in mixed-phase clouds under supercooled conditions as was previously thought (Vergara-Temprado et al. 2018). However, the high altitude temperatures near the tropical deep convective cloud tops can be less than $-38^{\circ} \mathrm{C}$ 


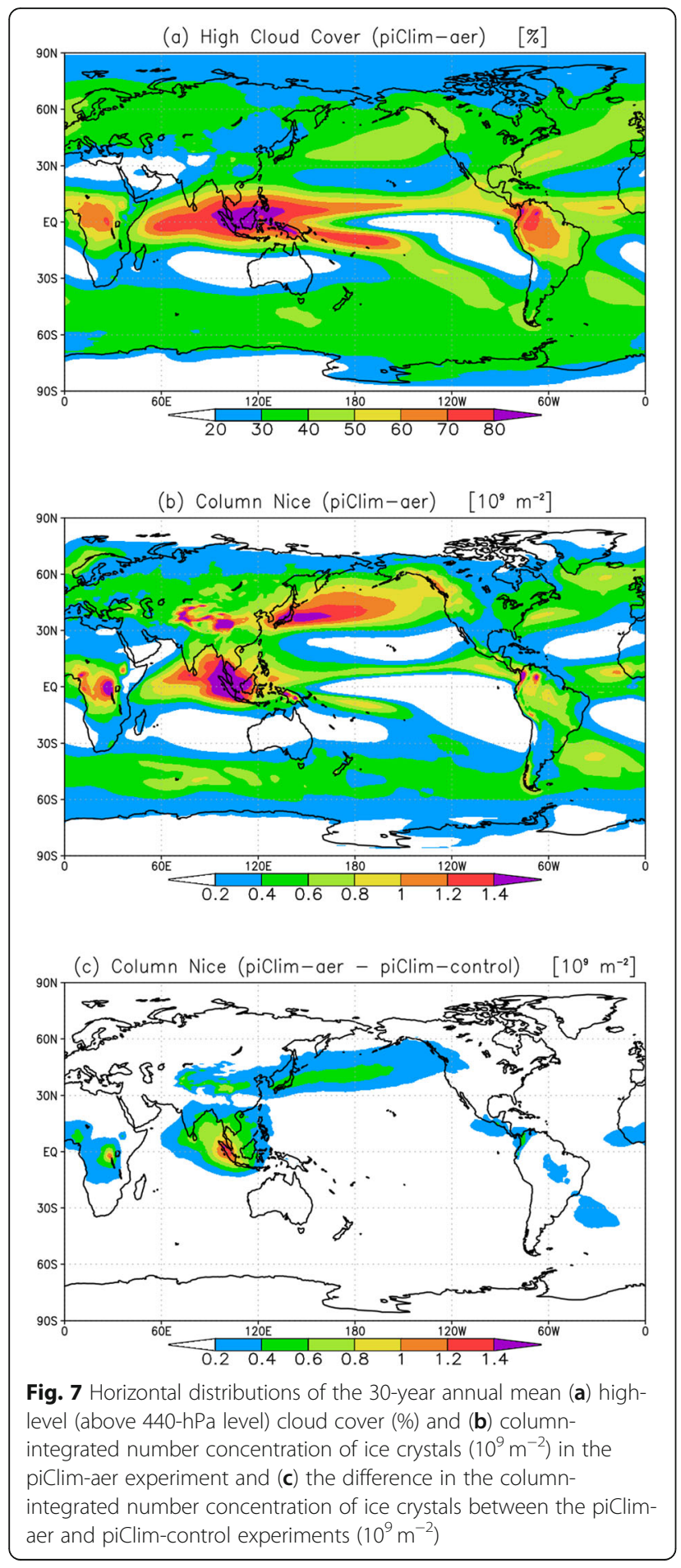

(Supplementary Fig. 4), and most aerosol particles would serve as INPs in such cold conditions (DeMott et al. 1999; Mahrt et al. 2018), suggesting the possible occurrence of interactions of aerosols with high-level ice clouds over the tropical convective regions. In terms of the radiation budget at the TOA, the net ERFs would mostly cancel out between the negative SW and positive
LW radiation; however, strong radiative heating of the atmosphere due to LW absorption by the high-level clouds could change the vertical atmospheric temperature profile (Supplementary Fig. 8a), leading to modifications in the large-scale atmospheric circulation and the hydrological cycle. A global modeling study implementing a parameterization of the aerosol effects on ice clouds estimated that the forcing due to anthropogenic $\mathrm{BC}$ was -0.3 W m${ }^{-2}$ (Penner et al. 2018), which is consistent with our estimate of the net ERFaci of BC, $-0.09 \mathrm{~W} \mathrm{~m}^{-2}$ (Table 2). Because there remain large uncertainties in the processes involved in the interactions of aerosols with ice clouds and the representations of the aerosol concentrations in the upper troposphere over the tropics in the model, the SW ERFaci and LW ERFaci values calculated in MRI-ESM2.0 might include quantitative uncertainties. Nevertheless, our results indicate the possible importance of the interactions of aerosols with ice clouds on atmospheric circulation and the hydrological cycle and suggest the importance of further studies of these interactions in high-level clouds over the tropics.

The piClim-BC experiment exhibits a positive net ERF at the TOA $\left(0.24 \mathrm{~W} \mathrm{~m}^{-2}\right)$ and a negative ERF at the surface $\left(-1.17 \mathrm{~W} \mathrm{~m}^{-2}\right)$ (Table 2$)$; therefore, the difference has a positive value $\left(1.41 \mathrm{~W} \mathrm{~m}^{-2}\right)$. This large radiative heating in the atmosphere is balanced by turbulent (latent and sensible) surface heat flux decreases, which correspond to the global mean precipitation decrease seen in the piClim-BC experiment. Although the spatial distributions of $\mathrm{BC}$ and precipitation are globally inhomogeneous, precipitation decreases could extend the $\mathrm{BC}$ lifetimes due to the weaker wet deposition processes because BC lifetimes are primarily controlled by wet removal from the atmosphere by precipitation (Oshima et al. 2012). Longer BC lifetimes could cause further radiative heating effects due to high-level clouds, which could represent a positive feedback process. On the other hand, stabilized atmosphere by radiative heating leads to a weakening of the upward mass flux of cumulus convection (Supplementary Fig. 8b), which could partially reduce the upward transport of $\mathrm{BC}$ to the upper troposphere. Because the climate responses to $\mathrm{BC}$ are complex, it is important to quantify the global energy budget perturbations caused by BC (e.g., Suzuki and Takemura 2019), particularly for models that represent the interactions of aerosols with ice clouds; however, the energy balance is not the focus of this study and will therefore be discussed in a future study.

Note that the aerosol processes controlling the spatial distributions of $\mathrm{BC}$ have nonlinearities in MRIESM2.0. For example, the conversion rate of $\mathrm{BC}$ from hydrophobic $\mathrm{BC}$ to hydrophilic $\mathrm{BC}$ (i.e., $\mathrm{BC}$ aging; see the "Methods" section) depends on the sulfate production rate. In the piClim-BC experiment, smaller 
levels of preindustrial $\mathrm{SO}_{2}$ emissions led to lower sulfate production, which caused slower $\mathrm{BC}$ aging rates, followed by a reduced wet removal of $\mathrm{BC}$ and therefore longer $\mathrm{BC}$ lifetimes because hydrophobic $\mathrm{BC}$ is inefficiently removed from the atmosphere by precipitation. This is consistent with the longer global mean $\mathrm{BC}$ lifetime of 7.1 days in the piClim-BC experiment compared to that of 5.9 days in the piClim-aer experiment. These nonlinearities in the aerosol processes tend to lead to greater effects due to $\mathrm{BC}$ in the piClim-BC experiment.

(c) Surface albedo The SW ERFs due to changes in the surface albedo induced by $\mathrm{BC}$ are significantly positive over the Tibetan Plateau and the entire Arctic region (Fig. 4f) and are caused by the surface albedo reduction due to $\mathrm{BC}$ deposition on snow and sea ice. The SW ERFalbedo induced by OM and sulfate are smaller (Fig. 4i and l). As a result, the SW ERFalbedo induced by the total aerosols is primarily controlled by BC (Fig. 4c). The global mean net ERFalbedo from the total aerosols is slightly positive $\left(0.08 \mathrm{~W} \mathrm{~m}^{-2}\right)$ due to the large contribution from $\mathrm{BC}$ $\left(0.07 \mathrm{~W} \mathrm{~m}^{-2}\right)$ (Figs. 1 and 6). The influence of $\mathrm{BC}$ on radiation over the Arctic is described in the next section.

\section{Arctic ERFs}

The Arctic region is strongly influenced by climate change. Figure 8 shows the LW and SW ERFs, and their net values averaged over the Arctic region $\left(60-90^{\circ} \mathrm{N}\right)$ at the TOA estimated by each experiment. The Arctic mean ERF values at the TOA and at the surface are summarized in Table 3. The large positive Arctic mean net ERFs at the TOA are estimated to be $1.47 \mathrm{~W} \mathrm{~m}^{-2}$ for $\mathrm{CO}_{2} ; 0.61 \mathrm{~W} \mathrm{~m}^{-2}$ for $\mathrm{BC} ; 0.35 \mathrm{~W} \mathrm{~m}^{-2}$ for $\mathrm{CH}_{4} ; 0.32 \mathrm{~W}$ $\mathrm{m}^{-2}$ for the tropospheric ozone (piClim-O3); and 1.94 $\mathrm{W} \mathrm{m}^{-2}$ for the total anthropogenic agents (Fig. 8 and Table 3). In the Arctic, $\mathrm{BC}$ and $\mathrm{CH}_{4}$ are responsible for the second and third largest positive net ERFs, respectively, after $\mathrm{CO}_{2}$ (Table 3 and Fig. 8). Note that the SW ERF of BC at the TOA is positive in the Arctic mean but is negative in the global mean (Fig. 2). The Arctic mean SW ERFs of BC due to the ARI, ACI, and surface albedo effects are estimated to be $0.28 \mathrm{~W} \mathrm{~m}^{-2},-0.77 \mathrm{~W} \mathrm{~m}^{-2}$, and $1.08 \mathrm{~W} \mathrm{~m}^{-2}$, respectively, while those of the total aerosols are $-0.07 \mathrm{~W} \mathrm{~m}^{-2},-1.01 \mathrm{~W} \mathrm{~m}^{-2}$, and $0.24 \mathrm{~W}$ $\mathrm{m}^{-2}$, respectively, indicating the large contribution to the SW ERFs from the reduction in the surface albedo due to $\mathrm{BC}$ deposition on snow and sea ice over the Arctic. The large positive net ERFs at the TOA (e.g., $\mathrm{CO}_{2}, \mathrm{BC}$, $\mathrm{CH}_{4}$, and the total anthropogenic agents) may be responsible for the increases in the surface air

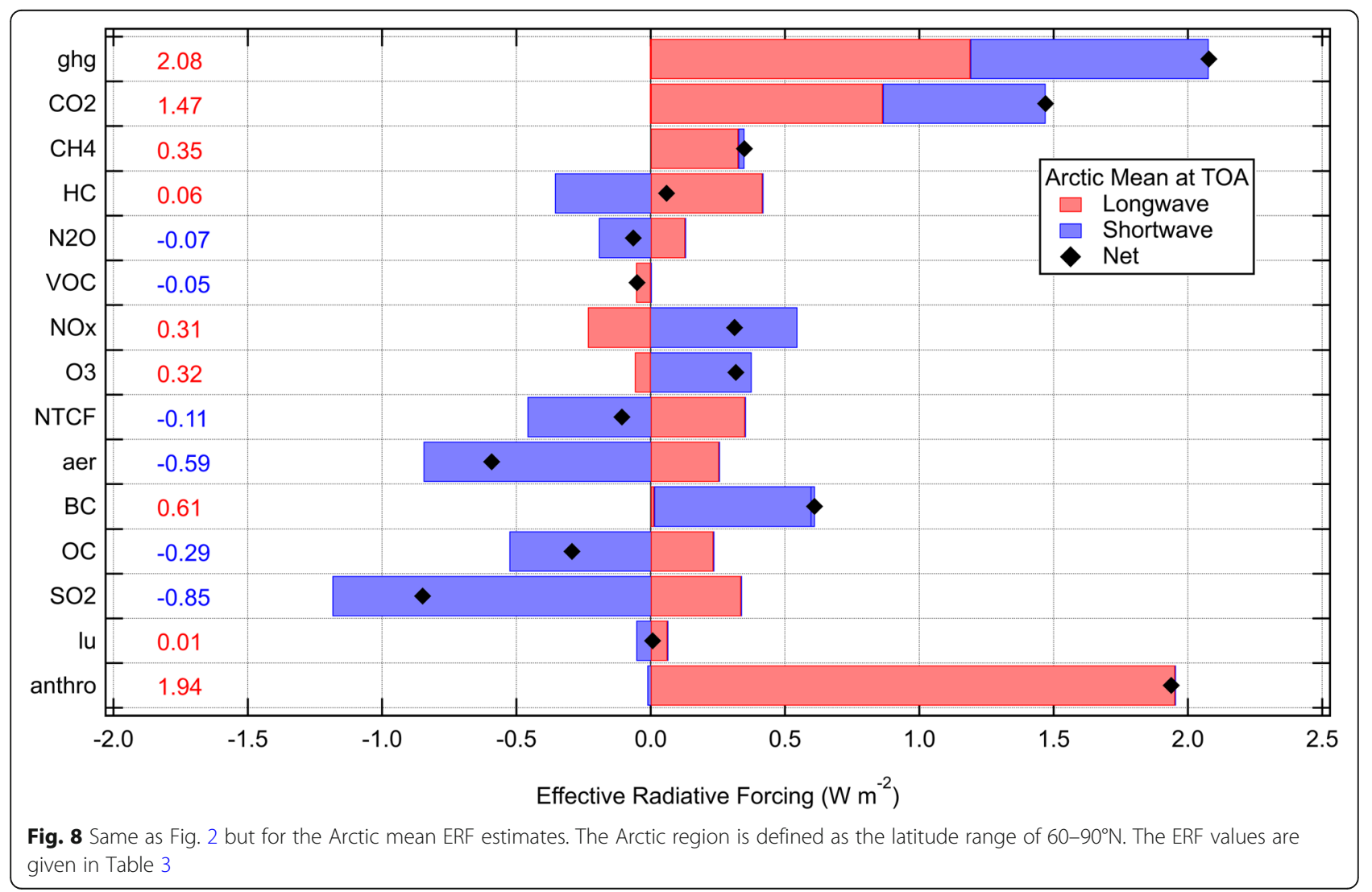


Table 3 Arctic $\left(60-90^{\circ} \mathrm{N}\right)$ annual mean effective radiative forcings and surface air temperatures of each experiment

\begin{tabular}{|c|c|c|c|c|c|c|c|}
\hline \multirow{2}{*}{$\begin{array}{l}\text { Experiment } \\
\text { name }\end{array}$} & \multicolumn{3}{|l|}{ ERF at TOA } & \multicolumn{3}{|l|}{ ERF at surface } & \multirow[t]{2}{*}{ SAT } \\
\hline & SW & LW & NET & SW & LW & NET & \\
\hline piClim-ghg & 0.89 & 1.19 & 2.08 & 0.18 & 1.07 & 1.26 & 0.41 \\
\hline piClim-4xCO2 & $2.51(0.61)$ & $3.57(0.86)$ & $6.09(1.47)$ & $-0.02(-0.00)$ & $2.78(0.67)$ & $2.76(0.67)$ & 1.25 \\
\hline piClim-CH4 & 0.02 & 0.33 & 0.35 & -0.13 & 0.29 & 0.16 & 0.09 \\
\hline piClim-HC & -0.36 & 0.42 & 0.06 & -0.05 & 0.21 & 0.16 & 0.02 \\
\hline piClim-N2O & -0.19 & 0.13 & -0.07 & -0.08 & 0.09 & 0.01 & -0.00 \\
\hline piClim-VOC & 0.00 & -0.06 & -0.05 & -0.14 & 0.11 & -0.03 & 0.04 \\
\hline piClim-NOx & 0.55 & -0.23 & 0.31 & -0.02 & -0.01 & -0.02 & -0.04 \\
\hline piClim-O3 & 0.38 & -0.06 & 0.32 & -0.09 & 0.11 & 0.02 & 0.04 \\
\hline piClim-NTCF & -0.46 & 0.35 & -0.11 & -1.03 & 0.40 & -0.63 & -0.09 \\
\hline piClim-aer & -0.85 & 0.25 & -0.59 & -0.97 & 0.46 & -0.51 & 0.03 \\
\hline piClim-BC & 0.60 & 0.01 & 0.61 & 0.09 & 0.36 & 0.45 & 0.22 \\
\hline piClim-OC & -0.53 & 0.23 & -0.29 & -0.50 & 0.03 & -0.47 & -0.01 \\
\hline piClim-SO2 & -1.19 & 0.34 & -0.85 & -0.97 & 0.34 & -0.63 & -0.10 \\
\hline piClim-lu & -0.05 & 0.06 & 0.01 & 0.02 & -0.09 & -0.07 & -0.02 \\
\hline piClim-anthro & -0.01 & 1.95 & 1.94 & -0.95 & 1.58 & 0.63 & 0.49 \\
\hline
\end{tabular}

SAT values are the differences in the 30-year annual mean values between each experiment and the piClim-control experiment. ERF and SAT values are given in units of $\mathrm{W} \mathrm{m}^{-2}$ and $\mathrm{K}$, respectively

ERF effective radiative forcing, TOA top of the atmosphere, SAT surface air temperature, SW shortwave, LW longwave, NET SW + LW, NTCF near-term climate forcers

${ }^{a}$ Values in parentheses are the ERFs of $\mathrm{CO}_{2}$ at the present-day concentrations as estimated from the piClim- $4 \times \mathrm{CO} 2$ experiment

temperatures over the Arctic (Table 3). Note that the temperature changes are limited because the experiments in this study were conducted using the prescribed SST and sea ice conditions. An understanding of the Arctic climate response requires more quantitative estimations of the ERFs taking into account the latent and sensible heat fluxes and the energy transport from lower latitudes in the atmosphere.

Figure 9 shows the spatial distributions of the net ERFs at the TOA over the Arctic and surrounding regions. The total anthropogenic net ERFs at the TOA exhibit substantially positive values over the entire Arctic region (Fig. 9a). The net ERFs of the well-mixed greenhouse gases at the TOA are composed of 57\% LW and $43 \%$ SW radiation over the Arctic (Fig. 8) and are generally spatially homogeneous both inside the Arctic and in the surrounding regions (Fig. 9b). The net ERFs of $\mathrm{BC}$ at the TOA are generally positive over the entire Arctic region, particularly around the edge of the springtime snow cover areas and the coastal region areas in Greenland (Fig. 9e) because BC deposition on snow over land and sea ice decreases the snow albedo, resulting in a decrease in the snow cover due to snow melting. Scattering aerosols, primarily sulfate aerosols, induce negative net ERFs both inside the Arctic and in the surrounding regions (Fig. 9f), and the spatial distributions of the ERFs generally depend on those of the sulfate in the atmosphere. These spatially dependent influences of greenhouse gases and aerosols (BC and sulfate) on the radiation are responsible for the positive net ERFs of the total anthropogenic agents over the entire Arctic region (Fig. 9a).

The results obtained in this study indicate the possible importance of greenhouse gases (e.g., $\mathrm{CO}_{2}$ and $\left.\mathrm{CH}_{4}\right)$ and $\mathrm{BC}$ aerosols on the Arctic climate. In particular, the interactions of $\mathrm{BC}$ aerosols with snow and ice could impact the radiative effects over the entire Arctic region. Decreases in the surface albedo due to $\mathrm{BC}$ deposition could influence the ERFs at the surface (Fig. 10); the net ERFs from $B C$ at the surface are substantially positive inside the Arctic region and negative outside the Arctic region (Fig. 10e), which could be partially responsible for the sharp contrasts in the total anthropogenic net ERFs at the surface between the areas inside (positive ERFs) and outside (negative ERFs) the Arctic regions (Fig. 10a). In the Arctic, $\mathrm{BC}$ and $\mathrm{CH}_{4}$ are responsible for the second and third largest positive net ERFs at the surface, respectively, after $\mathrm{CO}_{2}$ (Table 3 ). Because the Arctic climate has a significantly higher sensitivity to $\mathrm{BC}$ emitted within the Arctic compared to BC emitted in the surrounding regions (Sand et al. 2013), the results obtained in this study suggest that increases in direct $\mathrm{BC}$ emissions in the Arctic in the near future (e.g., ship emissions from new shipping routes and flaring emissions from oil and gas activities) could accelerate surface warming. 


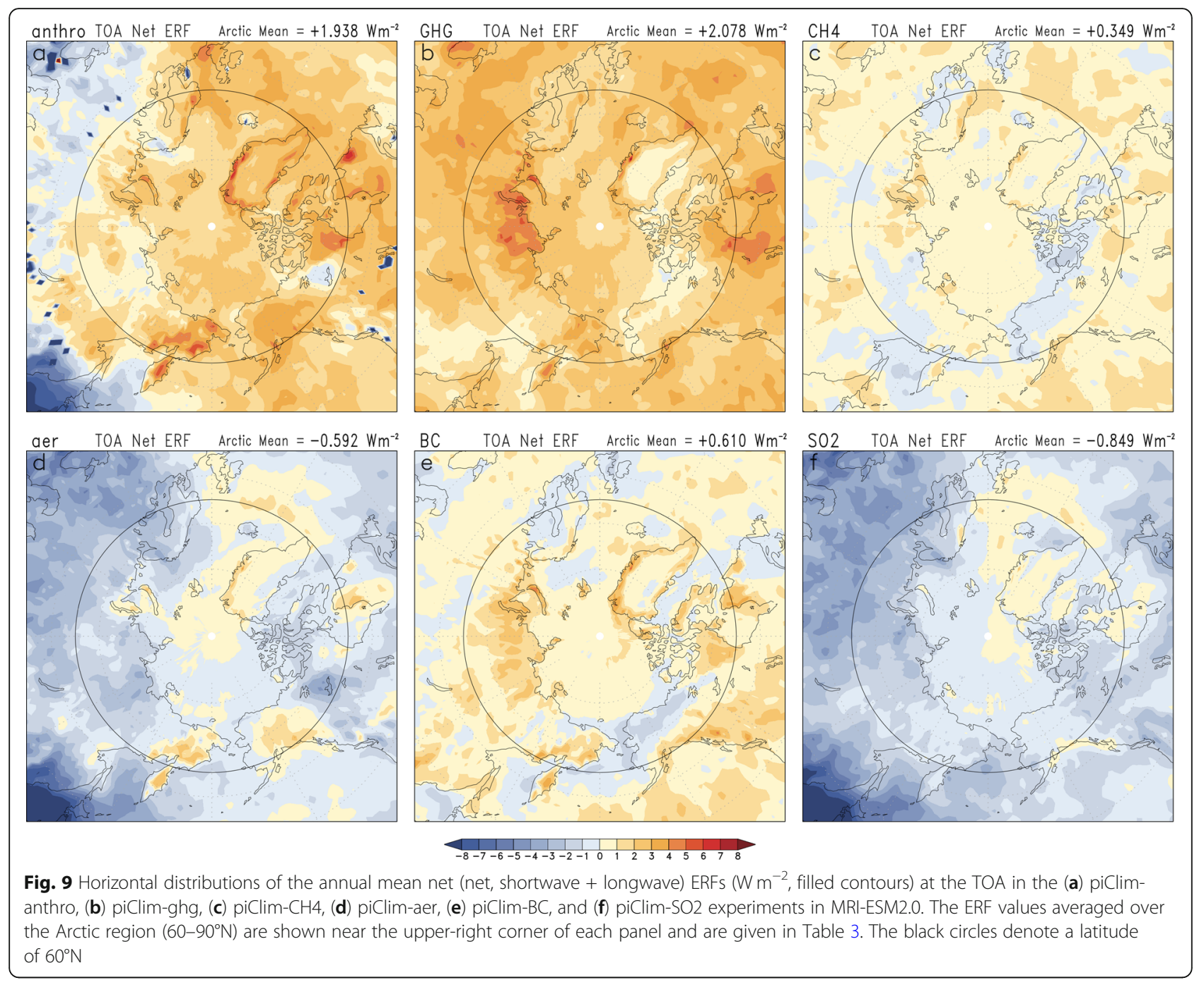

\section{Comparison of ERFs from different methods and previous} and other models

In this study, we use the method of Ghan (2013) to decompose the aerosol ERFs into the ARI, ACI, and surface albedo effects for SW and LW radiation; however, this method requires outputs from additional aerosolfree radiation calls in the model and additional computational time, making it difficult to conduct long calculations. Here, we compare our results to those derived using the APRP method of Taylor et al. (2007). Although the APRP method is an approximate technique, it is available for most of the climate model outputs, which facilitates comparisons to evaluations of the radiative effects of aerosols estimated by other models.

A comparison of the global mean ERF estimates at the TOA for the total aerosols (piClim-aer experiment) due to the ARI, ACI, and surface albedo effects in MRIESM2.0 using both methods is given in Table 4. Using the APPR method, the SW ERFari value is $0.17 \mathrm{~W} \mathrm{~m}^{-2}$ too negative and the SW ERFaci value is $0.23 \mathrm{~W} \mathrm{~m}^{-2}$ too positive, and they offset each other, and the total SW ERFari+aci value is similar (within a difference of 3\%) to those obtained using the method of Ghan (2013). The total LW ERFari+aci values derived by both methods are similar (within a difference of 3\%). The net ERFari+aci values are estimated to be $-1.30 \mathrm{Wm}^{-2}$ using the method of Ghan (2013) and - $1.21 \mathrm{~W} \mathrm{~m}^{-2}$ using the APRP method; this $7 \%$ difference is primarily due to the SW radiation. The biases in the SW ERFs using the APRP method are consistent with the results in Zelinka et al. (2014), who described possible reasons for the disagreements seen between the two methods in detail. The similar ERF estimates obtained using the two different methods lends credence to the validity of our decomposition results.

To quantify the impacts of the improvements to the aerosol and cloud processes in MRI-ESM2.0 on ERFs, we estimate the global mean ERFs and diagnose the ERFari, ERFaci, and ERFalbedo values using the APRP method in the sstClimAerosol experiment, which was 

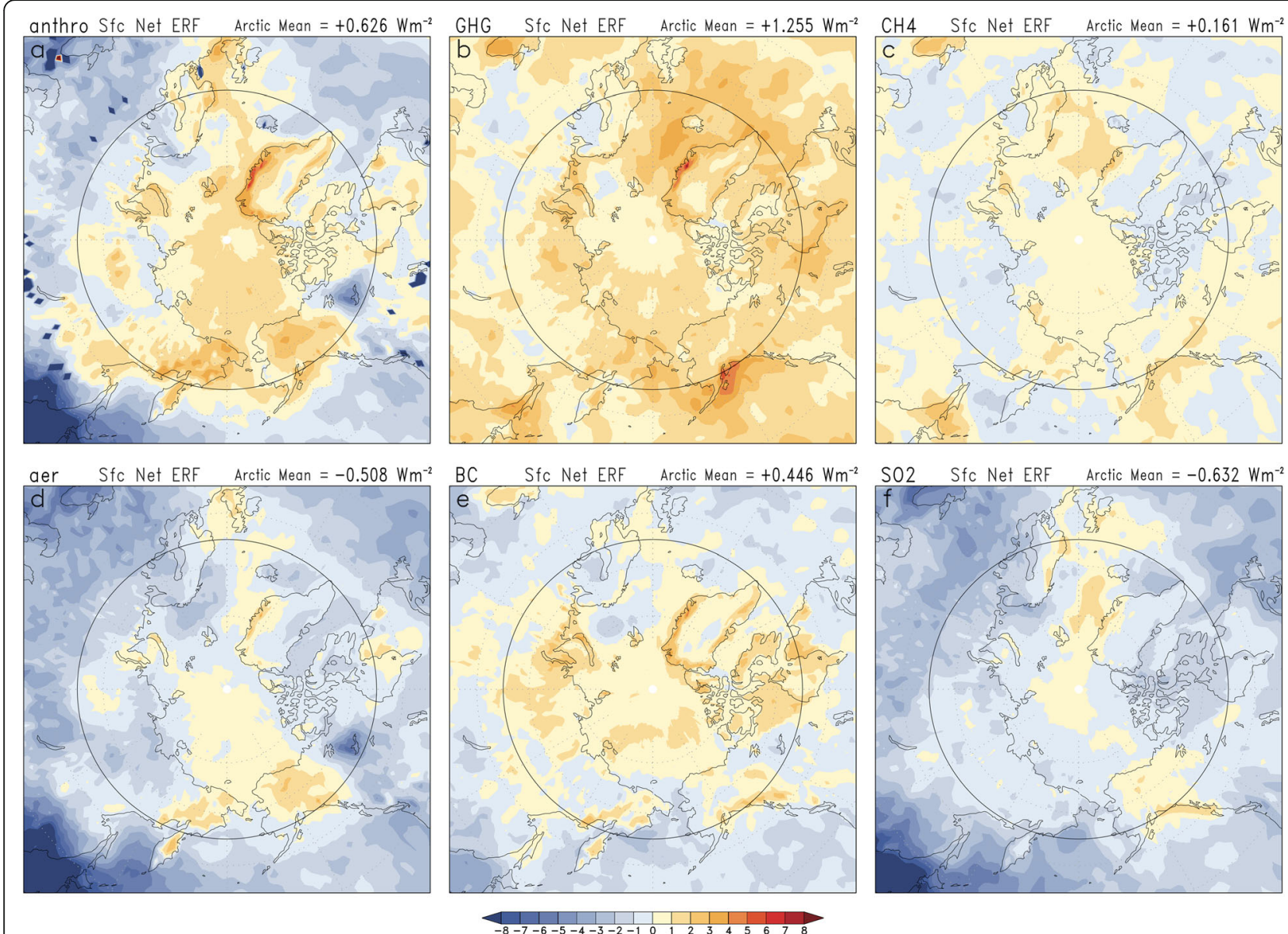

Fig. 10 Same as Fig. 9 but for the net (net, shortwave + longwave) ERFs at the surface

Table 4 Global annual mean effective radiative forcings of aerosols estimated by different methods and other models

\begin{tabular}{|c|c|c|c|c|c|c|c|c|c|c|c|c|c|c|c|}
\hline \multirow{3}{*}{$\begin{array}{l}\text { Model name } \\
\text { (Method) }\end{array}$} & \multicolumn{8}{|c|}{ SW ERF at TOA } & \multicolumn{3}{|c|}{ LW ERF at TOA } & \multicolumn{4}{|c|}{ NET ERF at TOA } \\
\hline & \multicolumn{3}{|l|}{ ARI } & \multicolumn{3}{|l|}{$\mathrm{ACl}$} & \multirow[t]{2}{*}{ ALB } & \multirow[t]{2}{*}{$\begin{array}{l}\mathrm{ARI}+ \\
\mathrm{ACl}\end{array}$} & \multirow[t]{2}{*}{ ARI } & \multirow[t]{2}{*}{$\mathrm{ACl}$} & \multirow[t]{2}{*}{$\begin{array}{l}\mathrm{ARI}+ \\
\mathrm{ACl}\end{array}$} & \multirow[t]{2}{*}{$\overline{A R I}$} & \multirow[t]{2}{*}{$\mathrm{ACl}$} & \multirow[t]{2}{*}{ ALB } & \multirow[t]{2}{*}{$\begin{array}{l}\mathrm{ARI}+ \\
\mathrm{ACl}\end{array}$} \\
\hline & scat & abs & sum & $\begin{array}{l}\text { scat + } \\
\text { abs }\end{array}$ & amt & sum & & & & & & & & & \\
\hline MRI-ESM2.0 (G13) & --- & --- & -0.32 & --- & --- & -2.47 & 0.05 & -2.79 & 0.00 & 1.49 & 1.49 & -0.32 & -0.98 & 0.08 & -1.30 \\
\hline $\begin{array}{l}\text { MRI-ESM2.0 } \\
\text { (APRP) }\end{array}$ & -0.76 & 0.28 & -0.49 & -1.86 & -0.38 & -2.24 & $\overline{-}-$ & -2.73 & 0.04 & 1.48 & 1.52 & -0.45 & -0.76 & --- & -1.21 \\
\hline $\begin{array}{l}\text { MRI-CGCM3 } \\
\text { (APRP) }\end{array}$ & -0.11 & 0.14 & 0.03 & -2.20 & -0.44 & -2.64 & 0.04 & -2.60 & 0.01 & 1.14 & 1.15 & 0.05 & -1.50 & --- & -1.46 \\
\hline $\begin{array}{l}12 \text { CMIP6 models } \\
\text { (APRP) Smith } \\
\text { et al. (2020) }\end{array}$ & $\begin{array}{l}-0.59 \pm \\
0.17\end{array}$ & $\begin{array}{l}0.26 \pm \\
0.12\end{array}$ & $\begin{array}{l}-0.33 \pm \\
0.20\end{array}$ & $\begin{array}{l}-0.84 \pm \\
0.49\end{array}$ & $\begin{array}{l}-0.15 \pm \\
0.26\end{array}$ & $\begin{array}{l}-0.99 \pm \\
0.49\end{array}$ & -- & $\begin{array}{l}-1.33 \pm \\
0.50\end{array}$ & $\begin{array}{l}0.12 \pm \\
0.06\end{array}$ & $\begin{array}{l}0.16 \pm \\
0.42\end{array}$ & $\begin{array}{l}0.27 \pm \\
0.40\end{array}$ & $\begin{array}{l}-0.21 \pm \\
0.18\end{array}$ & $\begin{array}{l}-0.84 \pm \\
0.30\end{array}$ & --- & $\begin{array}{l}-1.05 \pm \\
0.22\end{array}$ \\
\hline $\begin{array}{l}4 \text { CMIP6 models } \\
\text { (G13) Thornhill }\end{array}$ & --- & --- & --- & -- & --- & --- & --- & -- & --- & --- & --- & $\begin{array}{l}-0.17 \pm \\
0.15\end{array}$ & $\begin{array}{l}-0.96 \pm \\
0.25\end{array}$ & $\begin{array}{l}0.05 \pm \\
0.05\end{array}$ & $\begin{array}{l}-1.12 \pm \\
0.25\end{array}$ \\
\hline
\end{tabular}

Values estimated by MRI-CGCM3 are the forcings for the year 2000 relative to the year 1850 with CMIP5 emissions and those estimated by MRI-ESM2.0, the 12 CMIP6 models (Smith et al. 2020), and the 4 CMIP6 models (Thornhill et al. 2020) are the forcings at the year 2014 relative to the year 1850 with CMIP6 emissions (the piClim-aer experiment). Values estimated by the CMIP6 models are the multi-model means and standard deviations. All estimates are given in units of $\mathrm{W} \mathrm{m}^{-2}$. The $\mathrm{ACl}$ of the LW ERF is estimated to be the change in the LW cloud radiative effect, and the ARI of the LW ERF is estimated to be the residual of the total ERF minus the $\mathrm{ACl}$

ERF effective radiative forcing, TOA top of the atmosphere, SW shortwave, $L W$ longwave, NET SW + LW, $A R I$ aerosol-radiation interactions, $A C l$ aerosol-cloud interactions, $A L B$ surface albedo effects, scat scattering, abs absorption, amt cloud amount, G13 the method of Ghan (2013), APRP the approximate partial radiative perturbation (APRP) method of Taylor et al. (2007) 
performed using our previous model, MRI-CGCM3, in CMIP5. Note that the sstClimAerosol experiment did not include outputs from the aerosol-free radiation calls and that the ERFs in the experiment in CMIP5 were estimated for the year 2000 relative to the year 1850. The global mean ERF estimates for the total aerosols using the APRP method for MRI-ESM2.0 and MRI-CGCM3 are compared in Table 4. The SW ERFari value at the TOA is a slightly positive $0.03 \mathrm{~W} \mathrm{~m}^{-2}$ in MRI-CGCM3 compared to $-0.49 \mathrm{~W} \mathrm{~m}^{-2}$ in MRI-ESM2.0 due to the inappropriate treatment of the aerosol-radiation parameterization in MRI-CGCM3, which leads to a very small scattering effect of $-0.11 \mathrm{~W} \mathrm{~m}^{-2}$. In MRI-ESM2.0, this issue is corrected, and the scattering effect is -0.76 $\mathrm{W} \mathrm{m}{ }^{-2}$. The SW ERFaci value at the TOA is reduced by $0.40 \mathrm{~W} \mathrm{~m}^{-2}$, from $-2.64 \mathrm{~W} \mathrm{~m}^{-2}$ in MRI-CGCM3 to 2.24 $\mathrm{W} \mathrm{m}^{-2}$ in MRI-ESM2.0. On the other hand, the LW ERFaci value at the TOA is increased by $0.34 \mathrm{~W} \mathrm{~m}^{-2}$, from $1.14 \mathrm{~W} \mathrm{~m}^{-2}$ to $1.48 \mathrm{~W} \mathrm{~m}^{-2}$, as a result of the enhanced greenhouse effect of the tropical high-level clouds in MRI-ESM2.0 (Fig. 3b, not shown for MRICGCM3). As a result, the net ERFari+aci value at the TOA is $17 \%$ lower, from $-1.46 \mathrm{~W} \mathrm{~m}^{-2}$ in MRI-CGCM3 to $-1.21 \mathrm{~W} \mathrm{~m}^{-2}$ in MRI-ESM2.0. These results indicate that improvements to the aerosol, radiation, and cloud processes in MRI-ESM2.0 are responsible for the increases in the ARI effects (shifts to more negative) and decreases in the ACI effects (shifts to more positive).

The global mean ERF estimates at the TOA for the total aerosols due to the ARI, ACI, and surface albedo effects in MRI-ESM2.0 using the APRP method and the method of Ghan (2013) are compared to other CMIP6 model results using the respective methods reported in the literature (Table 4), i.e., 12 CMIP6 models using the APRP method (Smith et al. 2020) and 4 CMIP6 models using the method of Ghan (2013) (Thornhill et al. 2020). In comparison to the multi-model means of the 12 CMIP6 models using the APRP method, the SW ERFari value in MRI-ESM2.0 is $0.16 \mathrm{~W} \mathrm{~m}^{-2}$ too negative due to the greater scattering effects in MRI-ESM2.0 and the similar degree of absorption effects (Table 4), which leads to greater negative net ERFari value in MRIESM2.0 $\left(-0.45 \mathrm{~W} \mathrm{~m}^{-2}\right)$. The SW ERFaci and LW ERFaci values in MRI-ESM2.0 are more negative $\left(-2.24 \mathrm{~W} \mathrm{~m}^{-2}\right)$ and positive $\left(1.48 \mathrm{~W} \mathrm{~m}^{-2}\right)$, respectively, compared to the 12 CMIP6 model means $\left(-0.99 \mathrm{~W} \mathrm{~m}^{-2}\right.$ and $0.16 \mathrm{~W} \mathrm{~m}^{-2}$, respectively) because the aerosol effects on the highlevel ice clouds in the tropics contribute to the large ERFaci values in MRI-ESM2.0 and only a few of the 12 CMIP6 models treated the aerosol effects on the ice clouds (Smith et al. 2020). However, the net ERFaci value in MRI-ESM2.0 $\left(-0.76 \mathrm{~W} \mathrm{~m}^{-2}\right)$ is close to the 12 CMIP6 model mean value $\left(-0.84 \mathrm{~W} \mathrm{~m}^{-2}\right)$ because the large negative SW ERFaci and positive LW ERFaci mostly cancel each other out. In total, the net ERFari+ aci value in MRI-ESM2.0 $\left(-1.21 \mathrm{~W} \mathrm{~m}^{-2}\right)$ using the APRP method is approximately $15 \%$ more negative than the 12 CMIP6 model mean $\left(-1.05 \mathrm{~W} \mathrm{~m}^{-2}\right)$, and this difference is within the range of the standard deviation of the 12 CMIP6 models (Table 4). In addition, we compare the ERF values in MRI-ESM2.0 to the four CMIP6 model results using the method of Ghan (2013), although the number of models conducting the aerosolfree radiation calls was limited. The net ERFari value in MRI-ESM2.0 is $0.15 \mathrm{~W} \mathrm{~m}^{-2}$ too negative; however, the net ERFaci value $\left(-0.98 \mathrm{~W} \mathrm{~m}^{-2}\right)$ and the net ERF value due to the surface albedo changes $\left(0.08 \mathrm{~W} \mathrm{~m}^{-2}\right)$ are similar to the four CMIP6 model mean values $\left(-0.96 \mathrm{~W} \mathrm{~m}^{-2}\right.$ and $0.05 \mathrm{~W} \mathrm{~m}^{-2}$, respectively, and both are within a difference of $0.03 \mathrm{~W} \mathrm{~m}^{-2}$ ). In total, the net ERFari+aci value in MRI-ESM2.0 $\left(-1.30 \mathrm{~W} \mathrm{~m}^{-2}\right)$ using the method of Ghan (2013) is approximately 15\% more negative than the four CMIP6 model mean $\left(-1.12 \mathrm{~W} \mathrm{~m}^{-2}\right)$.

We also compare the global mean net ERFs at the TOA induced by the well-mixed greenhouse gases, aerosols, land-use change, and total anthropogenic components in MRI-ESM2.0 to the 12 CMIP6 model results (Smith et al. 2020); these ERF values are $3.02 \mathrm{~W} \mathrm{~m}^{-2}$, $1.22 \mathrm{~W} \mathrm{~m}^{-2},-0.19 \mathrm{~W} \mathrm{~m}^{-2}$, and $1.96 \mathrm{~W} \mathrm{~m}^{-2}$, respectively, in MRI-ESM2.0 (Table 1 and Fig. 1) and $2.87 \pm 0.18 \mathrm{~W}$ $\mathrm{m}^{-2},-1.04 \pm 0.23 \mathrm{~W} \mathrm{~m}^{-2},-0.08 \pm 0.14 \mathrm{~W} \mathrm{~m}^{-2}$, and $1.97 \pm 0.26 \mathrm{~W} \mathrm{~m}^{-2}$, respectively, in the 12 CMIP6 multimodel means. The differences between these values are within the ranges of the standard deviations in the 12 CMIP6 models; therefore, the overall net ERFs in MRIESM2.0 are consistent with the CMIP6 multi-model means.

\section{Conclusions}

We use MRI-ESM2.0 to estimate the ERFs from the anthropogenic forcing agents for present-day (year 2014) conditions relative to preindustrial (year 1850) conditions based on a suite of 30-year time-slice experiments with the prescribed preindustrial climatology of the SSTs and sea ice within the framework of RFMIP and AerChemMIP in CMIP6. The global mean total anthropogenic net ERF estimate at the TOA is $1.96 \mathrm{~W} \mathrm{~m}^{-2}$ and is composed of positive ERF from the well-mixed greenhouse gases $\left(3.02 \mathrm{~W} \mathrm{~m}^{-2}\right)$, negative ERF from the NTCFs $\left(-1.08 \mathrm{~W} \mathrm{~m}^{-2}\right)$, and slightly negative ERF from land-use changes $\left(-0.19 \mathrm{~W} \mathrm{~m}^{-2}\right)$. The ERF of the well-mixed greenhouse gases $\left(3.02 \mathrm{~W} \mathrm{~m}^{-2}\right)$ consists of forcings from $\mathrm{CO}_{2}\left(1.85 \mathrm{~W} \mathrm{~m}^{-2}\right), \mathrm{CH}_{4}\left(0.71 \mathrm{~W} \mathrm{~m}^{-2}\right)$, halocarbons $(0.30$ $\left.\mathrm{W} \mathrm{m}^{-2}\right)$, and $\mathrm{N}_{2} \mathrm{O}\left(0.16 \mathrm{~W} \mathrm{~m}^{-2}\right)$. The ERF value due to the NTCFs $\left(-1.08 \mathrm{~W} \mathrm{~m}^{-2}\right)$ consists of slightly positive ERFs from the tropospheric ozone $\left(0.07 \mathrm{~W} \mathrm{~m}^{-2}\right)$ and large negative ERFs from the total aerosols $(-1.22 \mathrm{~W}$ $\left.\mathrm{m}^{-2}\right)$, which consists of positive forcing from $\mathrm{BC}(0.24$ 
$\left.\mathrm{W} \mathrm{m}^{-2}\right)$ and negative forcings from sulfate $(-1.38 \mathrm{~W}$ $\mathrm{m}^{-2}$ ) and $\mathrm{OM}\left(-0.33 \mathrm{~W} \mathrm{~m}^{-2}\right)$.

We quantify the contributions to the ERFs at the TOA from the aerosol-radiation interactions, aerosolcloud interactions, and changes in the surface albedo due to aerosols using the method of Ghan (2013). The global mean total aerosol net ERF at the TOA ($1.22 \mathrm{~W} \mathrm{~m}^{-2}$ ) consists of a $23 \%$ contribution from ERFari $\left(-0.32 \mathrm{~W} \mathrm{~m}^{-2}\right)$, a $71 \%$ contribution from ERFaci $\left(-0.98 \mathrm{~W} \mathrm{~m}^{-2}\right)$, and a small contribution from ERFalbedo $\left(0.08 \mathrm{~W} \mathrm{~m}^{-2}\right)$. The total aerosol net ERFari $\left(-0.32 \mathrm{~W} \mathrm{~m}^{-2}\right)$ is dominated by $\mathrm{SW}$ radiation and consists of opposing contributions from lightabsorbing $\mathrm{BC}$ aerosols $\left(0.25 \mathrm{~W} \mathrm{~m}^{-2}\right)$, light-scattering sulfate $\left(-0.48 \mathrm{~W} \mathrm{~m}^{-2}\right)$, and organic aerosols $(-0.07$ $\mathrm{W} \mathrm{m}{ }^{-2}$ ), which are pronounced over the emission source regions. The total aerosol net ERFaci at the TOA $\left(-0.98 \mathrm{~W} \mathrm{~m}^{-2}\right)$ consists of ERFaci contributions due to $\mathrm{BC}\left(-0.09 \mathrm{~W} \mathrm{~m}^{-2}\right)$, OM $\left(-0.21 \mathrm{~W} \mathrm{~m}^{-2}\right)$, and sulfate $\left(-0.94 \mathrm{~W} \mathrm{~m}^{-2}\right)$ and is pronounced over the source and downwind regions, primarily due to the greater $\mathrm{CCN}$ activity of sulfate aerosols and the resulting large increases in the cloud droplet number concentrations in the low-level liquid clouds. The global mean total aerosol ERFalbedo at the TOA (0.08 $\left.\mathrm{W} \mathrm{m}^{-2}\right)$ is dominated by the $\mathrm{BC}$ contribution $(0.07 \mathrm{~W}$ $\mathrm{m}^{-2}$ ), which is caused by the decrease in the surface albedo due to $\mathrm{BC}$ deposition on snow and sea ice.

MRI-ESM2.0 shows the large influence of aerosols on high-level ice clouds and LW radiation. In particular, increases in the number concentration of ice crystals in high-level clouds (temperatures $<-38^{\circ} \mathrm{C}$ ) primarily due to anthropogenic BC aerosols by serving as INPs, particularly over the tropical convective regions, induces both substantial positive LW ERFaci and negative SW ERFaci in MRI-ESM2.0 (e.g., $1.54 \mathrm{~W} \mathrm{~m}^{-2}$ and $-1.63 \mathrm{~W}$ $\mathrm{m}^{-2}$, respectively, due to $\mathrm{BC}$ ). In terms of the radiation budget at the TOA, these distinct SW ERFaci and LW ERFaci can mostly cancel each other out, resulting in a smaller net ERFaci value (e.g., $-0.09 \mathrm{~W} \mathrm{~m}^{-2}$ due to $\mathrm{BC}$ ). However, high-level ice clouds over the tropical convective regions can cause significant LW radiative heating of the atmosphere, leading to modifications in the largescale atmospheric circulation and the hydrological cycle. This suggests the importance of anthropogenic INPinduced high-level ice cloud modifications on LW radiative heating. Note that the SW ERFaci and LW ERFaci estimated by MRI-ESM2.0 might include quantitative uncertainties because there remain large uncertainties in the parameterizations of the aerosol effects on ice clouds and the aerosol concentrations in the upper troposphere in the model. Nevertheless, our results suggest the potential importance of the interactions of aerosols with ice clouds at high altitudes over the tropics where high- level clouds are frequently present and that further studies on these interactions are required.

In the Arctic, $\mathrm{BC}$ and $\mathrm{CH}_{4}$ can provide the second and third largest contributions, respectively, to the positive ERFs after $\mathrm{CO}_{2}$ both at the TOA and at the surface. The reduction in the surface albedo due to $\mathrm{BC}$ deposition on snow over land and sea ice, which leads to a decrease in the snow cover due to snow melting, plays a major role in the Arctic mean SW ERFs of BC. The total anthropogenic net ERFs at the TOA exhibit substantially positive values over the entire Arctic region. The combination of the spatially homogeneous distributions of the net ERFs of the well-mixed greenhouse gases and the spatially inhomogeneous distributions of the net ERFs of the aerosols, primarily $\mathrm{BC}$ and sulfate, is responsible for the distributions of the total anthropogenic net ERFs over the Arctic. The greenhouse gases (e.g., $\mathrm{CO}_{2}$ and $\mathrm{CH}_{4}$ ) and $\mathrm{BC}$ aerosols likely have large impacts on the radiative effects and surface warming over the entire Arctic region.

The global mean ERF estimates at the TOA for the total aerosols in MRI-ESM2.0 are compared to other CMIP6 model results using the APRP method and the method of Ghan (2013). The comparisons indicate that MRI-ESM2.0 has particularly large positive LW ERFaci and negative SW ERFaci values due to the aerosol effects on high-level ice clouds over the tropical convective regions; however, these LW and SW ERFaci values mostly cancel each other out in the net ERFaci. Accordingly, the overall net ERFs in MRI-ESM2.0 are consistent with the CMIP6 multi-model means.

\section{Supplementary information}

Supplementary information accompanies this paper at https://doi.org/10. 1186/s40645-020-00348-w.

Additional file 1. Supplementary Figure 1. Horizontal distributions of the differences in the 30-year annual mean aerosol optical depths (AODs) between the (a) piClim-aer, (b) piClim-BC, (c) piClim-OC, and (d) piClimSO2 experiments and the piClim-control experiment. Note that the color scales are different in each panel. Supplementary Figure 2. Horizontal distributions of the 30-year annual mean (a-c) mid-level (440-680 hPa) cloud cover (\%), (d-f) low-level (below 680-hPa level) cloud cover (\%), (gi) liquid water path $\left(\mathrm{g} \mathrm{m}^{-2}\right)$, and $(\mathrm{j}-\mathrm{l})$ column-integrated number concentration of cloud droplets $\left(10^{9} \mathrm{~m}^{-2}\right)$ in the piClim-control experiment (left), the piClim-aer experiment (middle), and their differences (right). Note that the color scales are different in each panel. Supplementary Figure 3. Horizontal distributions of the 30-year annual mean (a-c) high-level (above 440-hPa level) cloud cover (\%), $(\mathrm{d}-\mathrm{f})$ ice water path $\left(\mathrm{g} \mathrm{m}^{-2}\right)$, and ( $\mathrm{g}-\mathrm{i})$ column-integrated number concentration of ice crystals $\left(10^{9} \mathrm{~m}^{-2}\right)$ in the piClim-control experiment (left), the piClim-aer experiment (middle), and their differences (right). Note that the color scales are different in each panel. Supplementary Figure 4. Vertical distributions of the 30-year annual zonal mean (a-c) cloud fraction (\%), (d-f) in-cloud ice water content $\left(\mathrm{mg} \mathrm{kg}^{-1}\right)$, and $(\mathrm{g}-\mathrm{i})$ in-cloud number concentration of ice crystals $\left(\mathrm{L}^{-1}\right)$ in the piClim-control experiment (left), the piClim-aer experiment (middle), and their differences (right). The solid black lines (left and middle panels) denote temperatures of $0^{\circ} \mathrm{C}$ and $-38^{\circ} \mathrm{C}$. The solid black lines (right panels) denote the values shown by the color coding in the 
piClim-control experiment (left panels). Note that the color scales are different in each panel. Supplementary Figure 5. Horizontal distributions of the differences in the 30-year annual mean number concentrations of the aerosols averaged within the range of 150-420 hPa between the (a) piClim-aer, (b) piClim-BC, (c) piClim-OC, and (d) piClim-SO2 experiments and the piClim-control experiment $\left(\mathrm{cm}^{-3}\right)$. The thick black lines denote 30-year annual mean high-level cloud cover of 70\% for the corresponding experiments. Note that the color scales are different in each panel. Supplementary Figure 6. Same as Supplementary Figure 5a but for boreal (a) winter, (b) spring, (c) summer, and (d) fall $\left(\mathrm{cm}^{-3}\right)$. Supplementary Figure 7. Same as Figure 7b but for boreal (a) winter, (b) spring, (c) summer, and (d) fall $\left(10^{9} \mathrm{~m}^{-2}\right)$. Supplementary Figure 8 . Vertical distributions of the differences in the 30-year annual global mean (a) temperature (K) and (b) upward mass flux of cumulus convection $\left(\mathrm{g} \mathrm{s}^{-1} \mathrm{~m}^{-2}\right)$ between the piClim-aer (black), piClim-BC (red), piClim-OC (green), and piClim-SO2 (blue) experiments and the piClim-control experiment.

\section{Abbreviations}

ACl: Aerosol-cloud interactions; AerChemMIP: Aerosol and Chemistry Model Intercomparison Project; AGCM: Atmospheric general circulation model; AMAP: Arctic Monitoring and Assessment Programme; APRP: Approximate partial radiative perturbation; AR: Assessment report; ARI: Aerosol-radiation interactions; BC: Black carbon; CCN: Cloud condensation nuclei; CMIP: Coupled Model Intercomparison Project; DECK: Diagnostic, Evaluation, and Characterization of Klima; ERF: Effective radiative forcing; ESGF: Earth System Grid Foundation; ESM: Earth System Model; INPs: Ice nucleating particles; IPCC: Intergovernmental Panel on Climate Change; JMA: Japan Meteorological Agency; LW: Longwave; MRI: Meteorological Research Institute; NTCFs: Near-term climate forcers; OC: Organic carbon; OGCM: Ocean-sea-ice general circulation model; OM: Organic matter; RFMIP: Radiative Forcing Model Intercomparison Project; SST: Sea surface temperature; SW: Shortwave; TOA: Top of the atmosphere; VOC: Volatile organic compound

\section{Acknowledgements}

We thank Mr. Satoru Koizumi sand Mr. Masaru Suga for their assistance in data processing.

\section{Authors' contributions}

NO designed the study, performed the model experiments and analysis, and wrote the manuscript incorporating input from all authors. SY performed the model experiments and analysis and gave many useful comments for writing the manuscript. MD performed the model experiments and analysis. $T K, T T$, and $K Y$ performed the model experiments. HK performed the analysis and helped in the interpretation of the results. All authors read and approved the final manuscript.

\section{Funding}

This work was supported by the Integrated Research Program for Advancing Climate Models (TOUGOU) grant number JPMXD0717935561 from the Ministry of Education, Culture, Sports, Science and Technology (MEXT), Japan; the Japan Society for the Promotion of Science (JSPS) KAKENHI (grant numbers JP26701004, JP15H05816, JP16H01772, JP18H03363, JP18H05292, JP19K03977, JP19H05699, and JP20K04070); the Environment Research and Technology Development Fund (JPMEERF20172003, JPMEERF14S11203, JPMEERF20202003, and JPMEERF20205001) of the Environmental Restoration and Conservation Agency of Japan; the Arctic Challenge for Sustainability II (ArCS II) grant number JPMXD1420318865; and a grant for the Global Environmental Research Coordination System from the Ministry of the Environment, Japan.

\section{Availability of data and materials}

The data used in this study (RFMIP and AerChemMIP data) is freely available from the CMIP6 repository on the Earth System Grid Foundation (ESGF) server (https://esgf-node.Inl.gov/search/cmip6/). The CMIP5 data is freely available from the CMIP5 repository on the ESGF server (https://esgf-node. Inl.gov/search/cmip5/). The source codes of MRI-ESM2.0 and MRI-CGCM3 are the property of MRI/JMA and not available to the general public. Access to the code can be granted upon request, under a collaborative framework between MRI and related institutes or universities.

\section{Competing interests}

The authors declare that they have no competing interest.

\section{Received: 31 December 2019 Accepted: 3 July 2020} Published online: 10 August 2020

\section{References}

Abdul-Razzak H, Ghan SJ (2000) A parameterization of aerosol activation: 2. Multiple aerosol types. J Geophys Res 105:6837. https://doi.org/10.1029/ 1999JD901161

Abdul-Razzak H, Ghan SJ, Rivera-Carpio C (1998) A parameterization of aerosol activation: 1. Single aerosol type. J Geophys Res 103:6123. https://doi.org/10. 1029/97JD03735

AMAP (2015) AMAP Assessment 2015: Black carbon and ozone as Arctic climate forcers. Arctic Monitoring and Assessment Programme (AMAP). Oslo, Norway. vii + 116 pp. [Available at http://www.amap.no/documents/doc/AMAPAssessment-2015-Black-carbon-andozone-as-Arctic-climate-forcers/1299.]

Aoki T, Kuchiki K, Niwano M, Kodama Y, Hosaka M, Tanaka T (2011) Physically based snow albedo model for calculating broadband albedos and the solar heating profile in snowpack for general circulation models. J Geophys Res 116:D11114. https://doi.org/10.1029/2010JD015507

Bigg EK (1953) The supercooling of water. Proc Phys Soc B 66:688-694

Bond TC, Doherty J, Fahey DW, Forster PM, Berntsen T, DeAngelo BJ, Flanner MG, Ghan S, Kärcher B, Koch D, Kinne S, Kondo Y, Quinn PK, Sarofim MC, Schultz MG, Schulz M, Venkataraman C, Zhang H, Zhang S, Bellouin N, Guttikunda SK, Hopke PK, Jacobson MZ, Kaiser JW, Klimont Z, Lohmann U, Schwarz JP, Shindell D, Storelvmo T, Warren SG et al (2013) Bounding the role of black carbon in the climate system: a scientific assessment. J Geophys Res-Atmos 118:5380-5552. https://doi.org/10.1002/jgrd.50171

Boucher O, Randall D, Artaxo P, Bretherton C, Feingold G, Forster P, Kerminen VM, Kondo Y, Liao H, Lohmann U, Rasch P, Satheesh SK, Sherwood S, Stevens B, Zhang XY (2013) Clouds and aerosols. In: Climate change 2013: the physical science basis. Contribution of Working Group I to the Fifth Assessment Report of the Intergovernmental Panel on Climate Change. In: Stocker TF, Qin D, Plattner G-K, Tignor M, Allen SK, Boschung J, Nauels A, Xia Y, Bex V, Midgley PM (eds). Cambridge University Press, Cambridge, United Kingdom and New York

Carslaw KS, Lee LA, Reddington CL, Pringle KJ, Rap A, Forster PM, Mann GW, Spracklen DV, Woodhouse MT, Regayre LA, Pierce JR (2013) Large contribution of natural aerosols to uncertainty in indirect forcing. Nature 503: 67-71. https://doi.org/10.1038/nature12674

Collins WJ, Lamarque J-F, Schulz M, Boucher O, Eyring V, Hegglin MI, Maycock A, Myhre G, Prather M, Shindell D, Smith SJ (2017) AerChemMIP: quantifying the effects of chemistry and aerosols in CMIP6. Geosci Model Dev 10:85-607. https://doi.org/10.5194/gmd-10-585-2017

Cotton WR, Tripoli GJ, Rauber RM, Mulvihill EA (1986) Numerical simulation of the effects of varying ice crystal nucleation rates and aggregation processes on orographic snowfall. J Clim Appl Meteorol 25:1658-1680. https://doi.org/10. 1175/1520-0450(1986)025<1658:NSOTEO>2.0.CO;2

DeMott PJ, Chen Y, Kreidenweis SM, Rogers DC, Sherman DE (1999) Ice formation by black carbon particles. Geophys Res Lett 26(16):2429-2432. https://doi. org/10.1029/1999GL900580

Eyring V, Bony S, Meehl GA, Senior CA, Stevens B, Stouffer RJ, Taylor KE (2016) Overview of the Coupled Model Intercomparison Project Phase 6 (CMIP6) experimental design and organization. Geosci Model Dev 9:1937-1958. https://doi.org/10.5194/gmd-9-1937-2016

Flanner MG, Zender CS, Randerson JT, Rasch PJ (2007) Present-day climate forcing and response from black carbon in snow. J Geophys Res 112:D11202. https://doi.org/10.1029/2006JD008003

Ghan SJ (2013) Technical Note: estimating aerosol effects on cloud radiative forcing. Atmos Chem Phys 13:9971-9974. https://doi.org/10.5194/acp-139971-2013

Hansen J, Nazarenko L (2004) Soot climate forcing via snow and ice albedos. Proc Natl Acad Sci U S A 101(2):423-428. https://doi.org/10.1073/pnas. 2237157100

Jacobson MZ (2002) Control of fossil-fuel particulate black carbon and organic matter, possibly the most effective method of slowing global warming. J Geophys Res 107(D19):4410. https://doi.org/10.1029/2001JD001376

Kaiho K, Oshima N (2017) Site of asteroid impact changed the history of life on Earth: the low probability of mass extinction. Sci Rep 9:14855. https://doi.org/ 10.1038/s41598-017-14199-x 
Kaiho K, Oshima N, Adachi K, Adachi Y, Mizukami T, Fujibayashi M, Saito R (2016) Global climate change driven by soot at the K-Pg boundary as the cause of the mass extinction. Sci Rep 6:28427. https://doi.org/10.1038/srep28427

Kärcher B, Hendricks J, Lohmann U (2006) Physically based parameterization of cirrus cloud formation for use in global atmospheric models. J Geophys Res 111:D01205. https://doi.org/10.1029/2005JD006219

Kärcher B, Lohmann U (2002) A parameterization of cirrus cloud formation: homogeneous freezing including effects of aerosol size. J Geophys Res 107: 4698. https://doi.org/10.1029/2001 JD001429

Kärcher B, Lohmann U (2003) A parameterization of cirrus cloud formation: Heterogeneous freezing. J Geophys Res 108:4402. https://doi.org/10.1029/ 2002JD003220

Kawai H, Yukimoto S, Koshiro T, Oshima N, Tanaka T, Yoshimura H, Nagasawa R (2019) Significant improvement of cloud representation in the global climate model MRI-ESM2. Geosci Model Dev 12:2875-2897. https://doi.org/10.5194/ gmd-12-2875-2019

Levkov L, Rockel B, Kapitza H, Raschke E (1992) 3D mesoscale numerical studies of cirrus and stratus clouds by their time and space evolution. Beitr Phys Atmos 65:35-58

Lohmann U (2002) Possible aerosol effects on ice clouds via contact nucleation. J Atmos Sci 59:647-656. https://doi.org/10.1175/1520-0469(2001)059<0647: PAEOIC $>2.0 . \mathrm{CO} ; 2$

Lohmann U, Diehl K (2006) Sensitivity studies of the importance of dust ice nuclei for the indirect aerosol effect on stratiform mixed-phase clouds. J Atmos Sci 63:968-982. https://doi.org/10.1175/JAS3662.1

Lohmann U, Feichter J, Chuang CC, Penner JE (1999) Prediction of the number of cloud droplets in the ECHAM GCM. J Geophys Res 104:9169-9198. https:// doi.org/10.1029/1999JD900046

Mahmood R, von Salzen K, Flanner M, Sand M, Langner J, Wang H, Huang L (2016) Seasonality of global and Arctic black carbon processes in the Arctic Monitoring and Assessment Programme models. J Geophys Res-Atmos 121 7100-7116. https://doi.org/10.1002/2016JD024849

Mahrt F, Marcolli C, David RO, Grönquist P, Barthazy Meier EJ, Lohmann U, Kanji ZA (2018) Ice nucleation abilities of soot particles determined with the Horizontal Ice Nucleation Chamber. Atmos Chem Phys 18:13363-13392. https://doi.org/10.5194/acp-18-13363-2018

Meyers MP, DeMott PJ, Cotton WR (1992) New primary ice-nucleation parameterizations in an explicit cloud model. J Appl Meteorol 31:708-721. https://doi.org/10.1175/1520-0450(1992)031<0708:NPINPI>2.0.CO;2

Murakami M (1990) Numerical modeling of dynamical and microphysical evolution of an isolated convective cloud - the 19 July 1981 CCOPE cloud. J Meteorol Soc Jpn 68:107-128. https://doi.org/10.2151/jmsj1965.68.2_107

Myhre G, Shindell D, Bréon F-M, Collins W, Fuglestvedt J, Huang J, Koch D, Lamarque J-F, Lee D, Mendoza B, Nakajima T, Robock A, Stephens G, Takemura T, Zhang H (2013) Anthropogenic and natural radiative forcing. In: Climate change 2013: the physical science basis. Contribution of Working Group I to the Fifth Assessment Report of the Intergovernmental Panel on Climate Change. In: Stocker TF, Qin D, Plattner G-K, Tignor M, Allen SK, Boschung J, Nauels A, Xia Y, Bex V, Midgley PM (eds). Cambridge University Press, Cambridge, United Kingdom and New York

Oshima N, Koike M (2013) Development of a parameterization of black carbon aging for use in general circulation models. Geosci Model Dev 6:263-282. https://doi.org/10.5194/gmd-6-263-2013

Oshima N, Koike M, Zhang Y, Kondo Y (2009a) Aging of black carbon in outflow from anthropogenic sources using a mixing state resolved model: 2. Aerosol optical properties and cloud condensation nuclei activities. J Geophys Res 114:D18202. https://doi.org/10.1029/2008JD011681

Oshima N, Koike M, Zhang Y, Kondo Y, Moteki N, Takegawa N, Miyazaki Y (2009b) Aging of black carbon in outflow from anthropogenic sources using a mixing state resolved model: model development and evaluation. J Geophys Res 114:D06210. https://doi.org/10.1029/2008JD010680

Oshima N, Kondo Y, Moteki N, Takegawa N, Koike M, Kita K, Matsui H, Kajino M, Nakamura H, Jung JS, Kim YJ (2012) Wet removal of black carbon in Asian outflow: Aerosol Radiative Forcing in East Asia (A-FORCE) aircraft campaign. J Geophys Res 117:D03204. https://doi.org/10.1029/2011JD016552

Penner JE, Zhou C, Garnier A, Mitchell DL (2018) Anthropogenic aerosol indirect effects in cirrus clouds. J Geophys Res Atmos 123:11,652-11,677. https://doi. org/10.1029/2018JD029204

Pincus R, Forster PM, Stevens B (2016) The Radiative Forcing Model Intercomparison Project (RFMIP): experimental protocol for CMIP6. Geosci Model Dev 9:3447-3460. https://doi.org/10.5194/gmd-9-3447-2016
Ramaswamy V, Boucher O, Haigh J, Hauglustaine D, Haywood J, Myhre G, Nakajima T, Shi GY, Solomon S (2001) Radiative forcing of climate change. In Climate change 2001: the scientific basis. Contribution of Working Group I to the Third Assessment Report of the Intergovernmental Panel on Climate Change. In: Houghton JT, Ding Y, Griggs DJ, Noguer M, van der Linden PJ, Dai X, Maskell K, Johnson CA (eds) , Cambridge, United Kingdom and New York, p 881

Sand M, Berntsen T, von Salzen K, Flanner M, Langner J, Victor D (2015) Response of Arctic temperature to changes in emissions of short-lived climate forcers. Nat Clim Chang. https://doi.org/10.1038/NCLIMATE2880

Sand M, Berntsen TK, Seland Ø, Kristjánsson JE (2013) Arctic surface temperature change to emissions of black carbon within Arctic or midlatitudes. J Geophys Res-Atmos 118:7788-7798. https://doi.org/10.1002/jgrd.50613

Smith CJ, Kramer RJ, Myhre G, Alterskjær K, Collins W, Sima A, Boucher O, Dufresne J-L, Nabat P, Michou M, Yukimoto S, Cole J, Paynter D, Shiogama H, O'Connor FM, Robertson E, Wiltshire A, Andrews T, Hannay C, Miller R, Nazarenko L, Kirkevåg A, Olivié D, Fiedler S, Pincus R, Forster PM (2020) Effective radiative forcing and adjustments in CMIP6 models. Atmos Chem Phys Discuss. https://doi.org/10.5194/acp-2019-1212 in review

Stohl A, Aamaas B, Amann M, Baker LH, Bellouin N, Berntsen TK, Boucher O, Cherian R, Collins W, Daskalakis N, Dusinska M, Eckhardt S, Fuglestvedt JS, Harju M, Heyes C, Hodnebrog Ø, Hao J, Im U, Kanakidou M, Klimont Z, Kupiainen K, Law KS, Lund MT, Maas R, MacIntosh CR, Myhre G, Myriokefalitakis S, Olivié D, Quaas J, Quennehen B et al (2015) Evaluating the climate and air quality impacts of short-lived pollutants. Atmos Chem Phys 15:10529-10566. https://doi.org/10.5194/acp-15-10529-2015

Suzuki K, Takemura T (2019) Perturbations to global energy budget due to absorbing and scattering aerosols. J Geophys Res-Atmos 124:194-2209. https://doi.org/10.1029/2018JD029808

Takemura T, Nozawa T, Emori S, Nakajima TY, Nakajima T (2005) Simulation of climate response to aerosol direct and indirect effects with aerosol transportradiation model. J Geophys Res 110:D02202. https://doi.org/10.1029/ 2004JD005029

Takemura T, Suzuki K (2019) Weak global warming mitigation by reducing black carbon emissions. Sci Rep 9:4419. https://doi.org/10.1038/s41598-019-41181-6

Taylor KE, Crucifix M, Braconnot P, Hewitt CD, Doutriaux C, Broccoli AJ, Mitchell JFB, Webb MJ (2007) Estimating shortwave radiative forcing and response in climate models. J Clim 20(11):2530-2543. https://doi.org/10.1175/JCLI4143.1

Taylor KE, Stouffer RJ, Meehl GA (2012) An overview of CMIP5 and the experiment design. Bull Am Meteorol Soc 93:485-498. https://doi.org/10. 1175/BAMS-D-11-00094.1

Thornhill GD, Collins WJ, Kramer RJ, Olivié D, O'Connor F, Abraham NL, Bauer SE, Deushi M, Emmons L, Forster P, Horowitz L, Johnson B, Keeble J, Lamarque J-F, Michou M, Mills M, Mulcahy J, Myhre G, Nabat P, Naik V, Oshima N, Schulz M, Smith C, Takemura T, Tilmes S, Wu T, Zeng G, Zhang J (2020) Effective radiative forcing from emissions of reactive gases and aerosols - a multimodel comparison. Atmos Chem Phys Discuss. https:/doi.org/10.5194/acp-2019-1205 in review

Vergara-Temprado J, Holden MA, Orton TR, O'Sullivan D, Umo NS, Browse J, Reddington C, Baeza-Romero MT, Jones JM, Lea-Langton A, Williams A, Carslaw KS, Murray BJ (2018) Is black carbon an unimportant ice-nucleating particle in mixed-phase clouds? J Geophys Res-Atmos 123:273-4283. https:// doi.org/10.1002/2017JD027831

Yoshimura H, Yukimoto S (2008) Development of a simple coupler (Scup) for Earth system modeling. Pap Meteorol Geophys 59:19-29

Yukimoto S, Adachi Y, Hosaka M, Sakami T, Yoshimura H, Hirabara M, Tanaka TY, Shindo E, Tsujino H, Deushi M, Mizuta R, Yabu S, Obata A, Nakano H, Koshiro T, Ose T, Kitoh A (2012) A new global climate model of the Meteorological Research Institute: MRI-CGCM3 -model description and basic performance. J Meteorol Soc Japan 90A:23-64. https://doi.org/10.2151/jmsj.2012-A02

Yukimoto S, Kawai H, Koshiro T, Oshima N, Yoshida K, Urakawa S, Tsujino H, Deushi M, Tanaka T, Hosaka M, Yabu S, Yoshimura H, Shindo E, Mizuta R, Obata A, Adachi Y, Ishii M (2019) The Meteorological Research Institute Earth System Model version 2.0, MRI-ESM2.0: description and basic evaluation of the physical component. J Meteor Soc Japan 97:931-965. https://doi.org/10. 2151/jmsj.2019-051

Zelinka MD, Andrews T, Forster PM, Taylor KE (2014) Quantifying components of aerosol-cloud-radiation interactions in climate models. J Geophys Res-Atmos 119:7599-7615. https://doi.org/10.1002/2014JD021710

\section{Publisher's Note}

Springer Nature remains neutral with regard to jurisdictional claims in published maps and institutional affiliations. 